TITLE:

\title{
COMPUTATIONAL MECHANICS OF VERTICAL SORTING OF SEDIMENT IN SHEETFLOW REGIME BY 3D GRANULAR MATERIAL MODEL
}

$\operatorname{AUTHOR}(S):$

HARADA, EIJI; GOTOH, HITOSHI

CITATION:

HARADA, EI JI...[et al]. COMPUTATIONAL MECHANICS OF VERTICAL SORTING OF SEDIMENT IN SHEETFLOW REGIME BY 3D GRANULAR MATERIAL MODEL. Coastal Engineering Journal 2008, 50(1): 19-45

\section{ISSUE DATE:}

2008

URL:

http://hdl.handle.net/2433/93448

\section{RIGHT:}

Electronic version of an article published as Coastal Engineering Journal, 50, 1, 2008, 19-45. DOl:

10.1142/S0578563408001715 @ copyright World Scientific Publishing Company http://www.worldscinet.com/cej/; This is not the published version. Please cite only the published version.; この論文は出版社版でありません。引用の際には 出版社版をご確認ご利用ください。 


\title{
COMPUTATIONAL MECHANICS OF VERTICAL SORTING OF SEDIMENT IN SHEETFLOW REGIME BY 3-D GRANULAR MATERIAL MODEL
}

\author{
Eiji HARADA \\ Department of Civil Engineering, Toyota National College of Technology, \\ 2-1 Eisei-cho, Toyota, Aichi, 471-8525, Japan \\ harada@toyota-ct.ac.jp \\ Hitoshi GOTOH(Corresponding author) \\ Department of Urban and Environmental Engineering, Kyoto University, \\ Katsura Campus, Nishikyo-ku, Kyoto, 615-8540, Japan \\ gotoh@mbox.kudpc.kyoto-u.ac.jp
}

\begin{abstract}
In a beach morphological process, such as a formation of a sand bar and a beach cusp, sediment sorting plays an important role. To describe a mechanism of sediment sorting directly, the movable bed simulator, which is a granular material model based on the distinct element method, is used. In this paper, a hydraulic experiment using an oscillatory water tunnel is conducted to track motion of sediment particles under vertical sorting in sheetflow regime. The three dimensional movable bed simulator is driven to track detailed motion of individual sediment particles numerically. Performance of the movable bed simulator as a tool of computational dynamics is shown by comparing simulated physical properties, such as series of instantaneous images, velocity profile and number-density distribution of sediment particles, with the result of the experiment.

Keywords : graded sediment; sheetflow regime; vertical sorting; 3-D movable bed simulator; granular material model; distinct element method.
\end{abstract}




\section{List of Symbols}

$$
\begin{aligned}
& A_{2}, A_{3} \quad=\text { two- and three-dimensional geometrical coefficients } \\
& C_{D} \quad=\text { drag coefficient } \\
& C_{M} \quad=\text { added mass coefficient } \\
& c_{n}, c_{s} \quad=\text { viscosity constants in the normal and tangential directions, respectively } \\
& d \quad=\text { reference particle diameter }\left(=d_{1}\right) \\
& d_{k} \quad=\text { diameter of a particle in the class } k \\
& d_{m} \quad=\text { mean diameter of particle } \\
& d_{p i} \quad=\text { diameter of the particle } i \\
& e_{n}, e_{s} \quad=\text { contact-force in normal and tangential directions, respectively } \\
& E \quad=\text { modulus of longitudinal elasticity } \\
& f_{o k}=\text { volumetric rate of a particle in the class } k \\
& \boldsymbol{F}_{\text {pINTi }}=\text { contact-force vector between particles of a particle } i \text { on the global coordinate } \\
& F_{\xi}, F_{n}, F_{\xi} \quad=\text { contact-force components between particles on the local coordinate } \\
& g \quad=\text { gravitational acceleration vector } \\
& \text { G } \quad \text { modulus of transverse elasticity } \\
& I_{p i} \quad=\text { moment of inertia of the particle } i \\
& k_{n}, k_{s} \quad=\text { spring constants in the normal and tangential directions, respectively } \\
& l, m, n \quad=\text { direction cosine } \\
& M \quad=\text { mass of particle } \\
& M_{\min } \quad=\text { mass of smallest particle } \\
& P_{n} \quad=\text { elasticity in normal direction } \\
& q_{* k} \quad=\text { averaged sediment transport rates in half-period of oscillation of the class } k \\
& s_{0} \quad=\text { damping rate }\left(=k_{s} / k_{n}\right) \\
& t \quad=\text { time } \\
& T \quad=\text { period of oscillatory flow } \\
& \boldsymbol{T} \quad=\text { external moment vector } \\
& {\left[T_{G L}\right]_{i j} \quad=\text { transformation matrix between global and local coordinates }}
\end{aligned}
$$




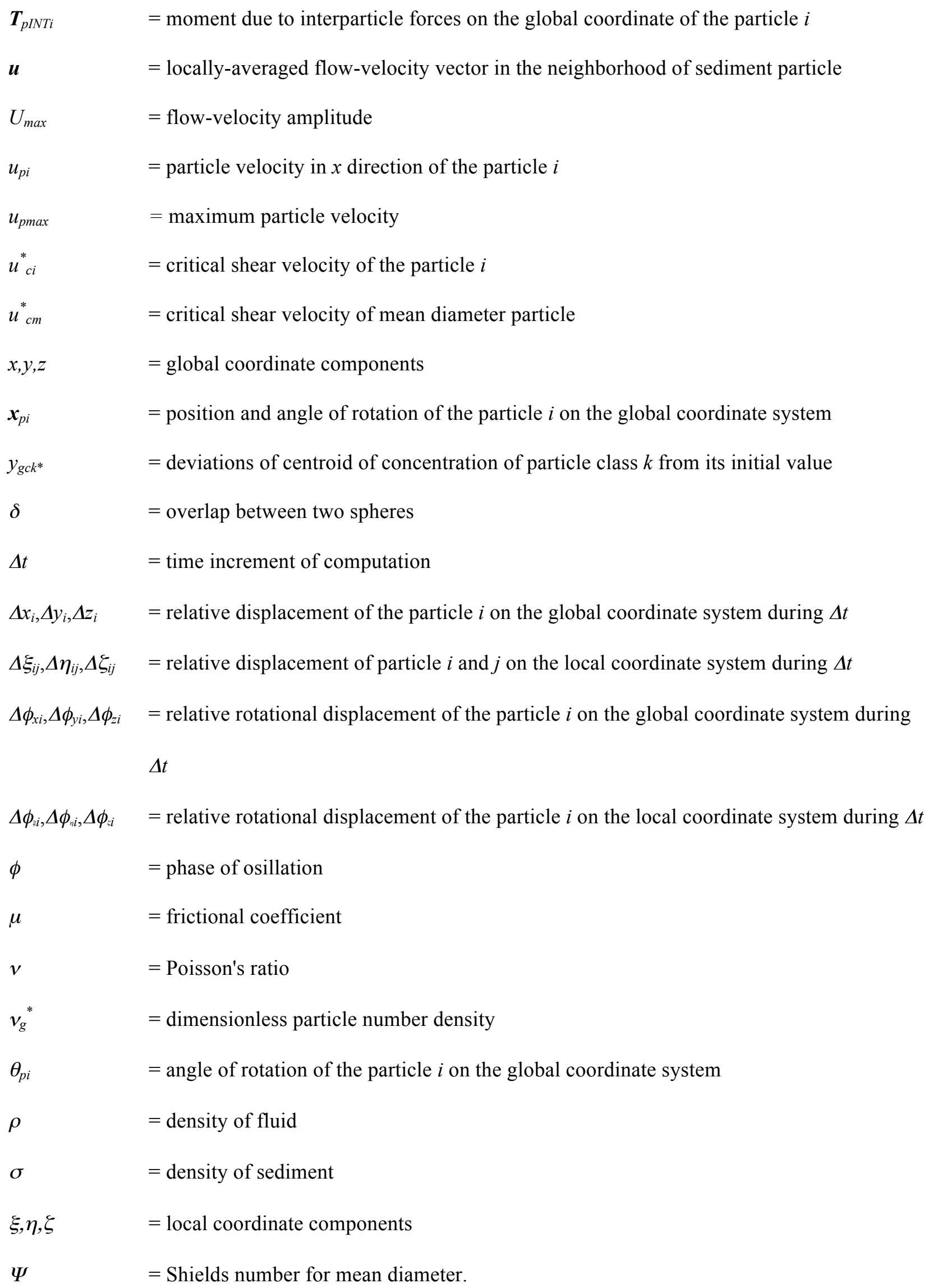




\section{Introduction}

Although beach sediment is well sorted in comparison to river sediment, some beach topographies are influenced by armoring, such as a sand bar or a beach cusp. Under sediment transport in sheetflow regime, in particular, a dynamic grading is the key to predict the sediment transport rate on the basis of physics. Since Horikawa et al.[1982], hydraulic experiments to clarify a mechanism of sheetflow sediment transport have been conducted. Suzuki et al.[1994] and Inui et al.[1995] examined the influence of mixing ratio of fine and coarse sediments on the sediment transport rate. Dibajnia and Watanabe[2000] observed a sheetflow sediment transport composed of fine and coarse sediments in order to examine its fundamental characteristics. Liu and Sato[2005] applied PIV techniques to estimate particle velocity in a sheetflow layer.

Because high sediment concentration in a sheetflow brings frequent interparticle collisions, a measurement of internal structure of a sheetflow layer is very difficult. For understanding the internal structure of a sheetflow layer, a granular material model based on the distinct element method, in which interparticle force of frequently colliding particles are calculated, is effective. The authors examined the mechanism of vertical grading in a sheetflow layer by the numerical movable bed. At first, both the size of the calculated domain and the resolution of simulation were restricted due to the limitation of computational capacity. A 2-D numerical movable bed was applied to the grading process of sheetflow layer composed by small and large two classes of plastic (artificial pearl) particles [Gotoh et al., 1996].

An oscillatory flow tunnel having a longer movable bed section than the previous one [Gotoh et al., 1996] was used to collect detailed experimental data on vertical grading at a developing and a fully-developed stage of armoring, such as unsteady and non-equilibrium behavior of armoring [Sakai et al., 2000, 2001]. Based on these experimental data, a model of the particle driving force was refined [Yeganeh et al., 2001]. These series of studies have been carried out by the 2-D numerical movable bed to clarify time averaged, or phase-averaged, characteristics of sheetflow layer. Gotoh et al.[2001a] found that detailed motion of sediment particles, such as trajectories, cannot be sufficiently reproduced by the 2-D numerical movable bed, because the transverse motion of particles is not negligible for tracking particles during few periods of oscillations. 
The variety of arrangements of particles and the degree of freedom of particle motion are smaller in the 2-D numerical movable bed in comparison with actual phenomena in a 3-D field, because all particles contact on the same plane in the 2-D numerical movable bed. Hence the development of 3-D numerical movable bed, which can express variety of interparticle contacts in actual 3-D field, is essential. Yoshida et al.[1988], McEwan and Heald[2001] and Shigematsu et al.[2002] proposed 3-D codes of the distinct element method. The authors also developed a numerical movable bed on the basis of the 3-D distinct element method [Gotoh et al., 2002]. However, as the analysis of internal structure of a grading process by the 3-D numerical movable bed has just began, detailed investigation on its performance through comparisons with experimental results must be conducted.

Recently, Blom et al.[2006] proposed a simple model of equilibrium vertical sorting in unidirectional flow. Schmeeckle and Nelson[2003] conducted a 3-D simulation of sorting based on the equation of motion of particles in unidirectional flow. In their model, particle/particle interaction was treated by solving equation of motion of jointed particles. As for the sheet flow sediment transport under oscillatory flow, Hsu et al. [2004] conducted a numerical simulation by a two-phase flow model based on a two-fluid model. Thaxton and Calantoni[2006] performed a numerical simulation by introducing desecrate particle model for sediment phase. They applied a hard sphere model different from the model of Gotoh et al.[2002], and found that larger particles migrate to the top of mobile bed, namely by reverse grading.

In this paper, results of hydraulic experiment using an oscillatory flow tunnel are compared with results of the 3-D numerical movable bed for vertical grading of three classes of plastic (artificial pearl) particles. The effectiveness of the 3-D numerical movable bed as a computational-dynamics tool of the grading process in a sheetflow sediment transport is clarified.

\section{Outline of Experiment of Sheetflow Sediment Transport}

\subsection{Experimental apparatus}

An acrylic-resin made oscillatory flow tunnel, which has a propeller flow-driving system in a closed pipe circuit, is used for the experiment (see Fig. 1). A $4.4 \mathrm{~m}$-long and $10.0 \mathrm{~cm}$-deep movable bed section is 
arranged at the center of the horizontal section which is $10.0 \mathrm{~m}$ long. Total length of the oscillatory flow tunnel is $12.0 \mathrm{~m}$. The cross section of the movable bed is $10.0 \mathrm{~cm}$ wide and $10.0 \mathrm{~cm}$ deep. Although an arbitrary wave pattern changing in onshore and offshore directions can be generated by a feedback control signal from electromagnetic flow meter, an oscillatory flow with a sinusoidal wave pattern is generated for simplicity in the characteristics of the flow field.

\subsection{Experimental conditions}

The test particle used in the experiment is an artificial pearl with specific gravity 1.318 . Small, middle and large three classes of plastic particles are mixed in a ratio shown in Table 1. The small, middle and large particles are $d_{1}=5.15 \mathrm{~mm}, d_{2}=9.88 \mathrm{~mm}$ and $d_{3}=15.60 \mathrm{~mm}$ in diameter, respectively. In the following sections, the diameter $d_{1}$ is treated as the standard particle size. Symbols in Table 1 are as follows: $d_{k}=$ diameter of particle; $f_{o k}=$ volumetric ratio of the class $k$; and $d_{m}=$ mean diameter of particle $(=10.20 \mathrm{~mm})$. Particles are mixed sufficiently so that each class of particle exists in equal ratio. The oscillatory flow was $T=5.0 \mathrm{~s}$ in period, $U_{\max }=85.0 \mathrm{~cm} / \mathrm{s}$ in flow-velocity amplitude at the center of cross section, and $\Psi=0.27$ in Shields number for mean diameter, in which frictional coefficient is estimated following Tanaka and Thu[1994]. The hydraulic condition of this experiment corresponds to the in the sheetflow regime as indicated by the previous study of Asano[1995]. In addition, typical sheetflow motion of movable bed was observed through the sidewall of the oscillatory flow tunnel.

\subsection{Method of analysis}

Moving particles are shot from the top and the side of a movable bed section using a high-speed video camera FASTCAM-PCI ${ }^{\mathrm{TM}}$, whose frame rate is $1 / 30 \mathrm{~s}$, with the maximum shutter speed $1 / 4000 \mathrm{~s}$. Images are downloaded onto a personal computer for analysis. The software Movie Ruler ${ }^{\mathrm{TM}}$ Ver 2.01, which is capable of commanding the automatic tracking of particle, was used for the measurement of particle velocities. The measurement of concentration distribution is conducted using the NIH-Image ${ }^{\mathrm{TM}}$ freeware with a preprocessing of image transformation to black-and-white mode[see Sakai et al., 2000]. 


\section{Simulation Model}

\subsection{3-D numerical movable bed}

The 3-D numerical movable bed [Gotoh et al., 2002; Gotoh, 2004] is a granular material model based on the distinct element method[Cundall and Strack, 1979]. The individual particle is tracked by the translational and rotational equations of motion as follows:

$$
\begin{gathered}
\rho\left(\frac{\sigma}{\rho}+C_{M}\right) A_{3} d_{p i}{ }^{3} \frac{\mathrm{d}^{2} \boldsymbol{x}_{p i}}{\mathrm{~d} t^{2}}=\frac{1}{2} \rho A_{2} d_{p i}{ }^{2} C_{D}\left|\boldsymbol{u}-\frac{\mathrm{d} \boldsymbol{x}_{p i}}{\mathrm{~d} t}\right|\left(\boldsymbol{u}-\frac{\mathrm{d} \boldsymbol{x}_{p i}}{\mathrm{~d} t}\right) \\
+\boldsymbol{F}_{p I N T i}+\rho\left(\frac{\sigma}{\rho}-1\right) A_{3} d_{p i}{ }^{3} \boldsymbol{g} \\
I_{p i} \frac{\mathrm{d}^{2} \boldsymbol{\theta}_{p i}}{\mathrm{~d} t^{2}}=-\boldsymbol{T}+\boldsymbol{T}_{p I N T i}
\end{gathered}
$$

in which, $\boldsymbol{x}_{p i}\left(x_{p i}, y_{p i}, z_{p i}\right), \theta_{p i}\left(\theta_{p x i}, \theta_{p y i}, \theta_{p z i}\right)=$ position and angle of rotation of the particle $i$ on the global coordinate $(x, y, z) ; \boldsymbol{F}_{p I N T i}\left(F_{p I N T x i}, F_{p I N T y i}, F_{p I N T z i}\right)=$ contact-force vector between particles on the global coordinate; $\boldsymbol{T}_{\text {pINTi }}\left(T_{p I N T x i}, T_{\text {pINTyi }}, T_{\text {pINTzi }}\right)=$ moment due to interparticle forces on the global coordinate; $\sigma$, $\rho=$ density of sediment and fluid, respectively; $C_{M}=$ added mass coefficient; $C_{D}=$ drag coefficient; $\boldsymbol{u}=$ locally-averaged flow-velocity vector in the neighborhood of sediment particle; $\boldsymbol{g}=$ gravitational acceleration vector; $I_{p i}=$ moment of inertia of the particle $i$; $A_{2}, A_{3}=$ two- and three-dimensional geometrical coefficients, respectively; and $d_{p i}=$ diameter of the particle $i$. The external moment vector $\boldsymbol{T}$ is set at zero, because a skin friction of particle due to surrounding flow is neglected in this simulation.

When two adjacent particles $i$ and $j$ satisfy the condition:

$$
L_{i j} \leq \frac{d_{i}+d_{j}}{2} ; \quad L_{i j}=\sqrt{\left(x_{i}-x_{j}\right)^{2}+\left(y_{i}-y_{j}\right)^{2}+\left(z_{i}-z_{j}\right)^{2}}
$$

then the contact force $\left(F_{\xi}, F_{\eta}, F_{\zeta}\right)$ between particles $i$ and $j$ is estimated by the Voigt model (spring-dashpot system, see Fig. 2) on the local coordinate $\left(\xi_{i}, \eta_{i}, \zeta_{i}\right)$ on the particle $i$. There are three components of contact force: a normal direction component $F_{\xi}$ and other two components $F_{\eta}$ and $F_{\zeta}$ on the tangential plane of two contacting particles as follows:

$$
\left.\begin{array}{c}
F_{\xi}(t)=e_{n}(t)+d_{n}(t) \\
e_{n}(t)=e_{n}(t-\Delta t)+k_{n} \cdot \Delta \xi_{i j} \quad ; \quad d_{n}(t)=c_{n} \cdot \frac{\Delta \xi_{i j}}{\Delta t}
\end{array}\right\}
$$




$$
\left.\begin{array}{c}
F_{\eta}(t)=e_{s \eta}(t)+d_{s \eta}(t) \\
e_{s \eta}(t)=e_{s \eta}(t-\Delta t)+k_{s} \cdot \Delta \eta_{i j} ; d_{s}(t)=c_{s} \cdot \frac{\Delta \eta_{i j}}{\Delta t}
\end{array}\right\}
$$

in which, $k_{n}, k_{s}=$ spring constants in the normal and tangential directions, respectively; $c_{n}, c_{s}=$ viscosity constants in the normal and tangential directions, respectively; $\Delta t=$ a time increment of computation; and $\left(\Delta \xi_{i j}, \Delta \eta_{i j}, \Delta \zeta_{i j}\right)=$ relative displacement of particle on the local coordinate $\left(\xi_{i}, \eta_{i}, \zeta_{i}\right)$ during $\Delta t$. In this model non-cohesive sediment is considered, and hence, a tensile force does not act on two contacting particles. Meanwhile, on tangential plane, frictional force works. To describe these characteristics, the contact force is modified as follows:

$$
\begin{gathered}
F_{\xi}(t)=0 \quad \text { when } e_{n}(t)<0 \\
F_{\eta}(t)=F_{\xi}(t)=\mu \cdot \operatorname{SIGN}\left(e_{n}(t), e_{s}(t)\right) \quad \text { when }\left|e_{s}(t)\right|>\mu \cdot e_{n}(t) \\
\operatorname{SIGN}(a, b)=\left\{\begin{array}{ccc}
|a| & \text { when } & b \geq 0 \\
-|a| & \text { when } & b<0
\end{array}\right.
\end{gathered}
$$

in which $\mu$ =frictional coefficient. Finally, the contact-force vector and the moment due to contact-force on the particle $i$ are written as follows:

$$
\left[\begin{array}{l}
F_{p I N T x i} \\
F_{p I N T y i} \\
F_{p I N T z i}
\end{array}\right]=-\sum_{j}\left[T_{G L}\right]_{i j}^{-1}\left[\begin{array}{l}
F_{\xi} \\
F_{\eta} \\
F_{\zeta}
\end{array}\right]_{i j} ;\left[\begin{array}{l}
T_{p I N T x i} \\
T_{p I N T y i} \\
T_{p I N T z i}
\end{array}\right]=\frac{d_{i}}{2} \sum_{j}\left[T_{G L}\right]_{j j}^{-1}\left[\begin{array}{c}
0 \\
F_{\zeta} \\
-F_{\eta}
\end{array}\right]_{i j}
$$

in which $\left[T_{G L}\right]_{i j}=$ transformation matrix between the global and local coordinates, details of which are shown in the Appendix. Equations 1 and 2 are solved explicitly to track the motion of particles considering the interparticle contacting forces evaluated by Eqs. 4, 5 and 6 .

\subsection{Model constants}

The authors [Gotoh et al., 2001b], proposed the conventional method of tuning of model constants $\left(k_{n}, k_{s}\right.$, $\left.c_{n}, c_{s}, \Delta t\right)$ in which spring and viscosity constants are determined by providing a time increment $\Delta t$ and a 
mass of particle. In this method, model constants are tuned in the 2-D numerical movable bed to bring good agreement of the computational results with the previous data of sediment transport rate in unidirectional flow condition. The estimation of the time required for computation is simple, because the time increment of computation, $\Delta t$, is given in this method. This tuning method is proposed for 2-D movable beds of uniform size particles. Hence, abnormal contact, such as significant overlap between particles causing violent repulsion, may arise if the size difference between large and small particles becomes significant. In order to be applied to the 3-D field having variety of contact condition between particles, trial and error must be performed in tuning. Therefore, in this paper, the Heltz's elasticity contact theory to control a significant overlap between particles is adopted. Same kind of procedures of model-constant tuning were adopted by Kiyama and Fujimura[1983] and Shigematsu et al. [2002].

Heltz's elasticity contact theory gives the overlap $\delta$ between two spheres in relation to an elasticity in normal direction $P_{n}$, modulus of longitudinal elasticity $E$ and Poisson's ratio $\nu(=0.3)$ as follows:

$$
\delta^{3}=\frac{9}{2} \frac{d_{i}+d_{j}}{d_{i} d_{j}}\left(\frac{1-v^{2}}{E}\right)^{2} P_{n}^{2}
$$

in which, $d_{i}, d_{j}=$ diameter of particle $i, j$ (see Fig. 3). By describing elasticity in normal direction $P_{n}$ as a function of spring constant $k_{n}$, such as:

$$
P_{n}=k_{n} \cdot \delta
$$

the spring constant $k_{n}$ can be written in the following form:

$$
k_{n}=\left\{\frac{2}{9} \frac{d_{i} d_{j}}{d_{i}+d_{j}}\left[\frac{E}{1-v^{2}}\right]^{2} P_{n}\right\}^{1 / 3}
$$

The spring constant $k_{s}$ is estimated using the ratio of the modulus of longitudinal elasticity $E$ against the modulus of transverse elasticity $G$ as follows:

$$
S_{o}=\frac{k_{s}}{k_{n}}=\frac{G}{E}=\frac{1}{2(1+v)}
$$

in which, $s_{0}=$ damping rate. On the other hand, viscosity constants, $c_{n}$ and $c_{s}$, are set to agree with the critical damping condition of the Voigt model in a single degree of freedom.

$$
c_{n}=2 \sqrt{M k_{n}} ; c_{s}=c_{n} \sqrt{s_{o}}
$$


in which, $M=$ mass of particle.

The modulus of longitudinal elasticity $E$, which is the key constants of tuning, is set at $E=5.0 \times 10^{5}$ $\mathrm{Pa}$ in order to reproduce the sediment transport rate of uniform sediment, the diameter of which is the mean diameter $d_{m}$ of small, middle and large plastic particles. The time increment of computation, $\Delta t$, is set in relation to the mass of the smallest particle $M_{\min }$ and the spring constant $k_{n}$ as follows:

$$
\Delta t \leq 2 \sqrt{\frac{M_{\min }}{k_{n}}}
$$

Particles tend to be accelerated easily in comparison to the hydraulic experiment, because an energy loss of the fluid by accelerating particles is not considered in this calculation. In other words, the multi-phase flow model is not applied to the liquid phase in this calculation. Therefore, a soft spring of low repulsion was applied to set the apparent restitution coefficient for the collision between particles smaller. This artifice brings an energy loss. Finally, all of the model constants are tuned to simulate the previous experiment of the sediment transport rate in unidirectional flow. One must pay attention to the fact that this approximation of the liquid phase model relates to the tuning of the solid-phase model constants. In other words, model constants of solid phase must be tuned again in future when a multi-phase flow model will be introduced in the description of the liquid phase.

\subsection{Model of the liquid phase}

The sheetflow sediment transport is recognized broadly to be a solid liquid multi-phase flow with high-density sediment. Although some multi-phase flow models (e.g. two fluid model by Asano[1990] and Dong and Zhang[1999], Euler-Lagrange coupling model by Yeganeh et al.[2000], and so on) should be introduced in the model of flow field, in this paper, the focus is on the description of the motion of solid-phase particles. For simplicity, the flow field is simulated using the $k$ - $\varepsilon$ turbulence model for a single-phase flow. The flow-velocity is calculated over the initial elevation of the seabed. The first grid point of the calculated flow-velocity region is located at $d / 4$ lower than the averaged elevation of the centroid of the seabed surface constituting particles. The instantaneous turbulent flow field is simulated using the simple Monte Carlo method, with referring turbulent intensity distribution calculated by the $k-\varepsilon$ 
model. Damping of flow velocity in the vicinity of a side wall, which is an acrylic board in the hydraulic experiment, is not considered. Uniform flow velocity distribution is assumed in transverse direction.

\subsection{Initial condition of simulation}

Figure 4 shows the calculated domain. Small, middle and large plastic particles are mixed in the same ratio as the experiment shown in Table 1. Total number of particles is 9,350: 8,017 small, 1,047 middle and 286 large particles. Firstly, particles are set on the node of 3-D grid, on which the position of each particle is set randomly, without an overlap with adjacent particles. Then the stable initial arrangement under the action of gravity is calculated[Gotoh, 2004]. A periodic boundary condition is imposed at the upstream and downstream sides of the calculated domain. Flat-board boundary condition, in which the modulus of longitudinal elasticity of the wall is $5.0 \times 10^{5} \mathrm{~Pa}$ and the Poisson's ratio is 0.3 for acrylic board, is applied on the side and bed walls. It was confirmed that the maximum step length of particles in the top layer during the half-period of an oscillation is shorter than the streamwise length of the calculated domain.

\section{Results of the Simulation}

\subsection{Centroid of concentration of particle-diameter class}

Figure 5 shows time series of the centroids of the concentration of particle-diameter classes in the experiment and the numerical simulation. The symbol $y_{g c k^{*}}$ in this figure shows vertical deviations of the centroid of concentration of particle-diameter class from its initial value. In the numerical simulation, tracking of the individual particle motion to calculate concentration centroid of each particle class is simple, while, in the experiment, the identification procedure of individual particles from each frame of video image is difficult. This is why a rather short period, from $t / T=0.0$ to 1.5 , in which a grading progresses conspicuously, is being treated herein.

The concentration centroid of particle-diameter class for overall width in transverse direction can be estimated using the numerical movable bed, while in the experiment, only particles moving in the neighborhood of the sidewall are observed. By considering this difference in the results of the simulation, time series of concentration centroid of particle-diameter class are calculated for the particles located in the $d_{3}$ (diameter of large particle)-wide layers, in the vicinity of the sidewall. 
The remarkable progresses of the grading can be confirmed in both of the experimental and numerical simulations, between $t / T=0.0$ and 1.0. The existence of this kind of fractional change of mixed-size particles was also simulated by Thaxton and Calantoni [2006]. Although a change of the concentration centroid due to a change in the oscillation velocity exists after $t / T=1.0$, the averaged level of a concentration centroid does not clearly increase. Namely, it is understood that the developing stage of grading is ending. Because in this calculation there are only three classes of particles, a small particle moves easily through the cavity between large particles. Consequently, the vertical sorting is promoted. On the other hand, when the natural sand grain-size distribution is wide, the cavity between large particles is filled up by variety of middle size particles. The downward motion of small particles is prevented by the middle-size particles. Consequently, the vertical sorting occurs more slowly than in the experiment. In the numerical simulation, the fluctuation of the concentration centroid of large particles is clearly visible in comparison with the small and middle particles. In the following sections, the processes between $t / T=0.0$ and 1.0 is termed developing stage of grading. Meanwhile, the processes between $t / T=1.0$ and 2.0 is termed fully developed stage of grading.

\subsection{Critical state of movement of each diameter class}

The critical state of movement of each diameter class in the experiment and the numerical simulation is shown in Fig. 6, in which previous experimental data by Egiazaroff[1965], Ashida and Michiue[1972] and Tanaka[1988] are also plotted. The critical bottom shear stress is estimated from the frictional velocity at the moment of initiation of the motion of particles, for each the class of particle diameter. Both the results of the experiment and the numerical simulation show an increased tendency of critical bottom shear with an increase in normalized particle diameter. This characteristics was similarly found in previous studies such as Egiazaroff[1965] and Ashida and Michiue[1972].

\subsection{Grading process}

Figure 7 shows side and top views of video images of the experiment and some snapshots of the numerical simulation in the developing stage of grading. Video image is limited to a narrow range in comparison with the numerical simulation due to the limitation in performance of the video camera. The top view 
shows that, through all phases, all classes of particles coexist in the surface layer. In the side view, a clear vertical grading is not found. A detailed observation of video images shows a decrease of small particles in the surface layer. In the snapshots of the simulation, the same trend, such as the decrease of the white colored small particles with an increase of the phase of oscillation is found.

Video images of the experiment and snapshots of the numerical simulation for the fully developed stages of grading are shown in Fig. 8. Top views of video images show that large and middle particles are prevailing in the surface layer. Side views show that the predominant size of particle is different in vertical direction. From top to bottom in the sheetflow layer, there are predominant layers of large, middle and small particles. In other words, it can be confirmed that an armor coat is formed as a result of vertical grading. Snapshots of numerical simulation results confirm the fully developed vertical grading found in the experiment, although the volumetric ratio of large particles in the surface layer is smaller than that in the experiment. As for the layer occupied by small particles at the bottom of the sheetflow layer $(-5.0<y / d<0.0)$, confirmed by both of the experiment and the numerical simulation in this paper, Dibajnia and Watanabe [2000] found similar results in their experiment of sediment sorting. This proves the effectiveness of the 3-D numerical movable bed for simulating the vertical grading phenomenon. The 2-D code [Gotoh et al., 2001a] does not properly reproduce the clear armoring reproduced in this experiment.

In the following sections, characteristics of the velocity profile and of the number density distribution are discussed for three phases: (i) an accelerating phase, (ii) a maximum velocity phase, and (iii) a decelerating phase.

\subsection{Velocity of particles}

Figure 9 shows mean velocity profiles of the fully-developed and the developing stages of grading. The velocity profile of particles for overall width in transverse direction can be estimated by the numerical movable bed, while, in the experiment, only particles moving in the neighborhood of the sidewall are observed. By considering this difference in the results of the simulation, the velocity profile of the particle is calculated for particles located in the $d_{3}$ (diameter of large particle)-wide layers, in the vicinity of the sidewall. Only the domain $0.0<y / d<5.0$, in which grading is very active, is shown in Fig. 9. In a developing process of a grading, all classes of particles are mixed homogeneously in the sheetflow layer. 
Hence, the momentum exchange generated by collision between particles is particularly active. In the accelerating phase $(\phi=2 / 8 \pi)$, velocity of small particle is larger than of the others, because small particles follow well the surrounding flow in comparison to large particles. At the maximum velocity phase $(\phi=4 / 8 \pi)$ and in the decelerating phase $\phi=6 / 8 \pi$, velocities of all classes of particles show almost the same distribution. Hence, the results of the numerical simulation agree well with the results of the experiment.

On the other hand, in the fully-developed stage, armoring of surface layer of sheetflow developed. Consequently, small particles are sheltered under the large and middle particles. Because of this developed armoring, in the accelerating phase $(\phi=2 / 8 \pi)$, the velocity profile of small particle does not reach the upper layer $(y / d>4.0)$, in both the experiment and the numerical simulation. At the maximum velocity phase $(\phi=4 / 8 \pi)$, an upward convex velocity profile is formed, and all classes of particles move almost in the same velocity range. A similar trend can be found in the numerical simulation. In the decelerating phase $(\phi=6 / 8 \pi)$, the upward convex velocity profile is also evident in both the experiment and the numerical simulation. Furthermore, with focusing on the phase $(\phi=4 / 8 \pi)$, the results of the experiment show that the velocity profile of particle has an inflection point in the developing stage of grading. Also, the upward convex velocity profile of the particle is shown in the fully-developed stage of grading. These characteristics are well reproduced by the numerical simulation.

\subsection{Number density distribution of particles}

Figure 10 shows dimensionless particle number density distributions of the developing and the fully-developed stages of grading. The dimensionless number density is calculated following the method proposed by Gotoh and Sakai[1997]. The experimental value of the particle number density was estimated from video images through the sidewall. Hence, in the data processing of the numerical simulation, a projected area of each class of particles on a vertical plane was calculated. As shown in Fig. 11, firstly, a thin layer between planes p1 and p2 is sliced (Fig.11(b) and (e)). Then, projection images are found for counting the occupied area of each class of particles (Fig.11(c) and (f)).

In the result of the experiment of the developing stage of a grading, the number density of small particle decreases with increasing phase in the surface layer of the sheetflow. In the same region, the 
number density of large particle increases, so that armoring is confirmed. Similar characteristics are reproduced in the numerical simulation. Furthermore, in the experimental result of the fully-developed stage, the formation of an armor coat is distinctly shown. Namely, in the sheetflow layer, one can seldom find small particles, while middle and large particles occupy the sheetflow layer. A similar characteristic is clearly found in the numerical simulation. In both of the numerical simulation and the experiment, changes of number density distribution with the development of grading are clearly reproduced.

The proposed method to estimate particle number density from 2-D projection-image data, is an effective technique, when there is a comparatively little void in the particle layer. However, when void increases, much more numbers of particles away from the sidewall are projected through voids. Therefore, voids in the vicinity of a sidewall tend to be regarded to be filled by particles, and consequently, the particle number density is overestimated. Peaks in particle number density in the surface layer of the fully developed stages (Fig. 10) are due to this reason. In the developing stage of grading, the estimation of the particle number density is possible rather precisely by 2-D projection image data, because small particles fill the voids between the middle and the large particles in the surface layer. In the fully-developed stage, the overestimation of the particle number density is unavoidable by the method using 2-D projection image data, because voids of the surface layer increase.

As mentioned above, it is inconvenient to estimate voids by images from the sidewall, but the particle number density is strictly estimated by counting existing particles in the measuring domain directly in the 3-D movable bed simulator. Number density distributions in the fully-developed stage of grading calculated for the results of the simulation is shown in Fig. 12. Peaks of particle number density in the neighborhood of the surface layer shown in Fig. 10 disappear. This kind of 3-D simulation code is a high-performance tool for the correct estimation of the particle number density, which is difficult using experimental video image processing.

When the 3-D simulation results are processed by the method similar to the one used to estimate the particle number density from 2-D projection image data, similar number density distribution to the experiment can be reproduced for both the developing and the fully-developed stages of grading. However, the estimation of the voids is insufficient in a 2-D crosssectional analysis. It is necessary to carry out strict estimation of voids by 3-D simulation so that the particle number density is precisely estimated. 


\subsection{Dimensionless sediment transport rate during half-period of oscillation}

Sediment transport rate is generally expressed as a relation depending on its averaged value during half-period of oscillation and the amplitude of the bottom shear stress. Averaged sediment transport rates over half-period of the oscillation, $q_{*}$, for the class of diameter " $i$ " are shown with their Shields numbers, $\Psi_{i}$, in Fig. 13. Empirical formula of Madsen-Grant[1976] and experimental results by Al-Salem[1993] and Asano[1995] are plotted on this figure. The Shields number and the dimensionless sediment transport rate are estimated in the same manner as Gotoh and Sakai[1997]. For the developing stage of grading, sediment transport rates for both the experiment and the simulation are estimated. The particle number density is evaluated from the 2-D projection image from a sidewall. For the fully-developed stage of a grading, the sediment flux is calculated directly from the results of 3-D simulation.

As for the developing stage of grading, although sediment transport rates of small particles in the experiment and the simulation show some differences, the trend of the upward slant to the right found in the experiment is well reproduced by the numerical simulation. On the other hand, in the results of the numerical simulation of the fully developed stage of grading, the sediment transport rate of large particle increases in comparison to the developing stage, because most of the surface layer is occupied by large particles. A remarkable difference is recognized for sediment transport rate of small particle, between the developing and the fully developed stages. The sediment transport rate of small particle in the fully developed stage is smaller than that of the developing stage, since small particles are sheltered by the middle and the large particles, due to the development of the armor coat.

\section{Internal Structure of the Sheetflow Layer}

The 3-D numerical movable bed can emulate the internal structure of a movable bed, which is difficult to investigate by experiment. Distributions of average velocity and snapshots of instantaneous image of sheetflow layer at the phase $\phi=2 / 8 \pi$. for both of the developing and the fully-developed stages are shown in Fig. 14 in order to discuss the influence of the sidewall to the movable bed. In this figure, the domain in the vicinity of a sidewall, which has the thickness of the diameter of the large particle, is called "wall neighborhood", while the domain $(0.0425 \mathrm{~m}<z<0.0575 \mathrm{~m})$ around the central part of the movable bed, 
which has a thickness of diameter of large particle, is called "central region". The snapshots in the central region are cross sectional images at $z=0.05 \mathrm{~m}$.

The velocities of large and middle particles in the wall neighborhood are smaller than those in the central region, in the developing stage of grading. This may be caused by a decrease in the degree of freedom of motion of large particles, because large particle are restricted by the flat sidewall. Void is easily forming between the large particles and flat sidewall. The small particle, which tends to pass through voids left between large particles, is easily accelerated. In the wall neighborhood, large particles must stay in contact with the fixed flat sidewall, while in the central region, there is no contact point around large particle with the fixed solids. Hence, a restriction of large particle in the central region is smaller than in the wall neighborhood. The arrangement of particles in the central region is denser than that in the wall neighborhood. Therefore, all particles tend to move together in the central region. On the other hand, in the fully-developed stage of grading, velocity distribution near the wall shows almost the same distribution as that of the central region. In the fully-developed stage of grading, although particles are influenced by the fixed sidewall, the presence of small particles, which is easily accelerated, is extremely reduced in the surface layer due to a developed armoring. In both the central region and the wall neighborhood, large particles govern the transport in the surface layer. Hence, the difference between the velocity distribution of particles in the central region and the wall neighborhood is smaller in the fully-developed stage of grading.

\section{Concluding Remarks}

The mechanism of vertical grading of the sheetflow sediment transport is investigated from both of the numerical simulation by the 3-D numerical movable bed and the experiment. Motion of particles in both of the developing and the fully-developed stages of the grading of sediment is discussed for the velocity profile of particle, the number-density distribution of particle and the sediment transport rate.

Results of the numerical simulation using the 3-D numerical movable bed reproduce reasonably the sediment transport rate of each class of diameter and the particle motion in sheetflow layer, which are observed in the experiment on vertical grading. In addition, the accuracy of the particle number density estimation from 2-D projection images of particles in the vicinity of the sidewall is discussed. Estimation 
from 2-D projection images is insufficient in the fully-developed stage of grading, in which void in the movable bed increases. In such case, direct estimation by 3-D numerical simulation is necessary. Furthermore, the influence of the sidewall on particle motion, which is impossible to be measured in experiments of this stage, is investigated using the 3-D numerical movable bed.

Comparing to the natural sediment having continuous and broader gradation, the three classes of particle size treated in this paper represents extreme simplification. While, a simple condition having a discrete distribution of particle size provides grading clearly different than the continuous size-distribution of natural sediment. This is why, a simple particle-size distribution is employed in this paper to test a numerical model. However, even for the case of the natural sediment with continuous and broader gradation, the governing mechanism of the particle-particle interaction is the same. Hence, the numerical model in this paper could be feasible for natural sediment condition.

Refinement of the liquid phase flow model, such as the introduction of the two-way multi-phase-flow model into the liquid phase model and the modeling of turbulence modulation due to contained sediment, could be considered for future work. The authors anticipate that the numerical movable bed will be playing a significant role in a computational science of sediment transport.

\section{Acknowledgement}

The authors would like to express their appreciation for the valuable comments of Dr. Tetsuo Sakai, Professor Emeritus, Kyoto University.

\section{Appendix: Transformation Matrix}

For the transformation matrix $\left[T_{G L}\right]_{i j}$, the global coordinate $(x, y, z)$ and the local coordinate $\left(\xi_{i}, \eta_{i}, \zeta_{i}\right)$ of particle $i$ are defined as follows. The $\xi_{i}$ axis is defined positive in the direction from the center of particle $i$ to the center of particle $j$. Two planes are introduced: the plane including the center of particle $i$ parallel to the tangential plane of the particles $i$ and $j$; and the plane parallel to the $x y$-plane. Among the lines of intersection of these two planes, the line passing the center of the particle $i$ is defined as the $\eta_{i}$-axis. Finally, 
the $\zeta_{i}$-axis is defined to form the right-hand coordinate system with axes $\xi_{i}$ and $\eta_{i}$. A positive angular displacement is defined to march a right-hand thread to the positive direction of each axis. A schematic expression of the local coordinate system is shown in Fig. 15.

There are two sets of transformation matrix, because two right-hand coordinate systems $\left(\xi_{i}, \eta_{i}, \zeta_{i}\right)$ and $\left(\xi_{i}{ }^{\prime}, \eta_{i}{ }^{\prime}, \zeta_{i}{ }^{\prime}\right)$ are used under the rule mentioned above. Each one of these two matrices can express the coordinate transformation for all directions, except one. The transformation matrix is written as:

$$
\left[T_{G L}\right]_{i j}=\left[\begin{array}{ccc}
l_{i} & m_{i} & n_{i} \\
\frac{-m_{i}}{\sqrt{l_{i}^{2}+m_{i}^{2}}} \frac{l_{i}}{\sqrt{l_{i}^{2}+m_{i}^{2}}} & 0 \\
\frac{-l_{i} n_{i}}{\sqrt{l_{i}^{2}+m_{i}^{2}}} \frac{-m_{i} n_{i}}{\sqrt{l_{i}^{2}+m_{i}^{2}}} \sqrt{l_{i}^{2}+m_{i}^{2}}
\end{array}\right]
$$

or

$$
\left[T_{G L}\right]_{i j}=\left[\begin{array}{ccc}
l_{i} & m_{i} & n_{i} \\
\frac{m_{i}}{\sqrt{l_{i}^{2}+m_{i}^{2}}} \frac{-l_{i}}{\sqrt{l_{i}^{2}+m_{i}^{2}}} & 0 \\
\frac{l_{i} n_{i}}{\sqrt{l_{i}^{2}+m_{i}^{2}}} \frac{m_{i} n_{i}}{\sqrt{l_{i}^{2}+m_{i}^{2}}}-\sqrt{l_{i}^{2}+m_{i}^{2}}
\end{array}\right]
$$

in which, $l_{i}, m_{i}, n_{i}=$ direction cosine defined as:

$$
l_{i}=-\frac{x_{i}-x_{j}}{L_{i j}} \quad ; \quad m_{i}=-\frac{y_{i}-y_{j}}{L_{i j}} \quad ; \quad n_{i}=-\frac{z_{i}-z_{j}}{L_{i j}}
$$

When the cosine of the angle between the $\eta_{i}$-axis and the $y$-axis is positive, the transformation matrix is given by Eq. A.1. Otherwise, the transformation matrix is given by Eq. A.2.

Under the condition $x_{i}=x_{j}$ and $y_{i}=y_{j}$, the lines of intersection of the above-mentioned two planes cannot be defined, since the two planes are parallel. For this condition, both of $\eta_{i}$-and $\zeta_{i}$-axes exist on the plane parallel to the $x y$-plane and are indeterminate. Then, by defining the $\eta_{i}$ axis parallel to the $y$-axis, the transformation matrix is written as: 


$$
\left[T_{G L}\right]_{i j}=\left[\begin{array}{ccc}
0 & 0 & -1 \\
0 & 1 & 0 \\
1 & 0 & 0
\end{array}\right] \text { or }\left[T_{G L}\right]_{i j}=\left[\begin{array}{ccc}
0 & 0 & 1 \\
0 & 1 & 0 \\
-1 & 0 & 0
\end{array}\right]
$$

instead of Eqs. A.1 or A.2, respectively. By this transformation matrix, the desplacement and the angular displacement on the global coordinates are transformed into those of the local coordinates as follows:

$$
\begin{gathered}
{\left[\begin{array}{l}
\Delta \xi_{i j} \\
\Delta \eta_{i j} \\
\Delta \xi_{i j}
\end{array}\right]=\left[T_{G L}\right]_{i j}\left[\begin{array}{l}
\Delta x_{i}-\Delta x_{j} \\
\Delta y_{i}-\Delta y_{j} \\
\Delta z_{i}-\Delta z_{j}
\end{array}\right]+\left[\begin{array}{cc}
0 & 0 \\
\Delta \phi_{\zeta i} & \Delta \phi_{\zeta j} \\
-\Delta \phi_{\eta i}-\Delta \phi_{\eta j}
\end{array}\right]\left[\begin{array}{l}
d_{i} / 2 \\
d_{j} / 2
\end{array}\right]} \\
{\left[\begin{array}{l}
\Delta \phi_{\xi i} \\
\Delta \phi_{\eta i} \\
\Delta \phi_{\xi i}
\end{array}\right]=\left[T_{G L}\right]_{i j}\left[\begin{array}{c}
\Delta \phi_{x i} \\
\Delta \phi_{y i} \\
\Delta \phi_{z i}
\end{array}\right]}
\end{gathered}
$$

\section{References}

Al-Salem, A. A. [1993] "Sediment transport in oscillatory boundary layers under sheet-flow conditions," Master Thesis, Technical University of Delft.

Asano, T. [1990] "Two-phase flow model on oscillatory sheet flow," Proc. 22nd International Conf. on Coastal Eng., ASCE, 2372-2384.

Asano, T. [1995] "Sediment transport under sheet-flow conditions," Jour. Waterways, Port, Coastal and Ocean Engrg., 121(5): 1-8.

Ashida, K. and Michiue, M. [1972] "Study on hydraulic resistance and bed-load transport rate in alluvial streams," Proc. JSCE, 206: 59-69(in Japanese).

Blom, A., Parker, G., Ribberink, J.S. and de Vriend, H.J.[2006] "Vertical sorting and the morphodynamics of bed-form-dominated rivers: An equilibrium sorting model," Jour. Geophysical Res., Earth Surface, 111, Art. No. F01006, 2006.

Cundall, P. A. and Strack, O. D. L. [1979] "A discrete numerical model for granular assemblies," Geotechnique, 29: 47-65.

Dibajnia, M. and Watanabe, A. [2000] "Moving layer thickness and transport rate of graded sand," Proc. of 27th International Conf. on Coastal Eng., ASCE, 2752-2765.

Dong, P. and Zhang, K. [1999] "Two-phase flow modeling of sediment motions in oscillatory sheet flow," Coastal Engineering, 36, 87-109.

Egiazaroff, I.V. [1965] "Calculation of nonuniform sediment concentrations," Jour. Hydraul. Div., ASCE, 91(HY4): 225-247.

Gotoh, H., Sakai, T. and Toyota, Y. [1996] "Vertical sorting of mixed-size sediment in sheet flow regime," Proc. 43rd Japanese Conf. on Coastal Eng., JSCE, 456-460(in Japanese). 
Gotoh, H. and Sakai, T. [1997] "Numerical simulation of sheetflow as granular material," Jour. of Waterway, Port, Coastal, and Ocean Engrg., ASCE, 123(6): 329-336.

Gotoh, H., Harada, E. and Sakai, T. [2001a] "Vertical sorting of graded sediment transport under oscillatory flow," Journal of Hydraulic, Coastal and Environmental Eng., JSCE, 691(II-57): 133-142(in Japanese).

Gotoh, H., Harada, E. and Sakai, T. [2001b] "Optimization of parameters in DEM-based numerical movable bed simulator," Journal of Hydraulic, Coastal and Environmental Eng., JSCE, 691(II-57): 159-164(in Japanese).

Gotoh, H., Harada, E. and Sakai, T. [2002] "3D numerical movable bed for simulating grading in sheetflow sediment transport," Proc. Coastal Eng., 49, JSCE, 471-475(in Japanese).

Gotoh, H. [2004] Computational mechanics of sediment transport (Morikita Shuppan Co. Ltd), (in Japanese).

Horikawa, K., Watanabe, A. and Katori, S. [1982] "Sediment transport under sheet flow condition," Proc. of 18th International Conf. on Coastal Eng., ASCE, 1335-1352.

Hsu, T.-J., Jenkins, J. T. and Liu, P. L.-F. [2004] "On two-phase sediment transport: sheet flow of massive particles,” Proc. R. Soc. London, Ser. A, 460(2048), doi:10.1098/rspa.2003.1273.

Inui, T., Dibajnia, M., Isobe, M. and Watanabe, A. [1995] "A transport rate formula for mixed-size sands and its application," Proc. 42nd Japanese Conf. on Coastal Eng., JSCE, 521-525(in Japanese).

Kiyama, H. and Fujimura, H. [1983] "Application of Cundall's discrete block method to gravity flow analysis of rock-like granular materials," Proc. JSCE, 333: 137-146(in Japanese).

Liu, H. and Sato, S. [2005] "Laboratory study on sheetflow sediment movement in the oscillatory turbulent boundary layer based on image analysis," Coastal Eng. J. 47(1): 21-40.

Madsen, O. S. and Grant, W. D. [1976] "Sediment transport in the coastal environment," Rep. No.209, Ralph M. Parsons Lab., MIT.

McEwan, I. K. and Heald, J. [2001] "Discrete particle modeling of entrainment from flat uniformly sized sediment beds," J. Hydraul. Eng., ASCE, 127 (7): 588-597.

Sakai, T., Gotoh, H., Oki, K. and Takahashi, T. [2000] "Vertical grading of mixed-size grains in sheetflow regime under oscillatory flow," Proc. of 27th International Conf. on Coastal Eng., ASCE, 2766-2779.

Sakai, T., Gotoh, H., Harada, E., Takahashi, T. and Hama Y. [2001] "Unsteady armoring in graded-sediment sheetflow under oscillatory flow," Proc. APCE 2001, Dalian, China, 766-775.

Schmeeckle, M.W. and Nelson, J.M. [2003] "Direct numerical simulation of bedload transport using a local, dynamic boundary condition," Sedimentology, 50 (2), pp. 279-301.

Shigematsu, T., Hirose, M. and Oda, K. [2002] "A numerical modeling of generation and propagation of water wave generated by landslide," Proc. of 28th International Conf. on Coastal Eng., ASCE, 1178-1190. 
Suzuki, K., Watanabe, A., Isobe, M. and Dibajnia, M. [1994] "Experimental study on transport of sediment with mixed-grain size due to oscillatory flow," Proc. 41st Japanese Conf. on Coastal Eng., JSCE, 356-360(in Japanese).

Tanaka, H., Katayama, Y., Kaga, M. and Suga, G. [1988] “Transport of bed load with non-uniform grain size," Proc. 35th Japanese Conf. on Coastal Eng., JSCE, 307-311(in Japanese).

Tanaka, H. and Thu, A. [1994] "Time-varying bottom friction due to wave and current interacting at an arbitrary angle," Coastal Eng. in Japan, 37(2): 137-151.

Thaxton, C. S. and Calantoni, J. [2006] "Vertical sorting and preferential transport in sheet flow with bimodal size distributions of sediment," Proc. ICCE2006, San Diego, pp. 1041-1050.

Yeganeh, A., Harada, E., Gotoh, H. and Sakai, T. [2001] "Reverse grading process of sheet-flow sediment transport with granular material model," Proc. of 2nd IAHR Symp. on River, Coastal and Estuarine Morphodynamics, Obihiro, Japan, 131-140.

Yeganeh, A., Gotoh, H. and Sakai, T. [2000] "Applicability of Euler-Lagrange coupling multiphase-flow model to bed-load transport under a high bottom shear," Jour. Hydraulic Res., 38(5): 389-398.

Yoshida, H., Masuya, H. and Imai, K. [1988] "Impulsive properties of falling rocks on sand-layers by means of Cundall's discrete block method," Journal of Structural Eng., JSCE, 392(I-9): 297-306(in Japanese).

Captions

Fig. 1Oscillatory flow tunnel

Fig. 2 Voigt model (spring-dashpot system)

Fig. 3 Heltz's elasticity contact theory

Fig. 4 Calculated domain

Fig. 5 Time series of centroids of concentration of particles

Fig. 6 Critical state of movement of each diameter class

Fig. 7 Comparison between experimental video images and computational snapshots in the developing stage of grading

Fig. 8 Comparison between experimental video images and computational snapshots in fully developed stage of grading

Fig. 9 Mean velocity profiles of sediment particles

Fig. 10 Dimensionless particle number density distributions

Fig. 11 Estimation of dimensionless particle number density

Fig. 12 Dimensionless particle number density distributions

Fig. 13 Sediment transport rate

Fig. 14 Comparison of the internal structure of sheetflow layer

Fig. 15 Local coordinate

Table 1 Sediment diameter class 


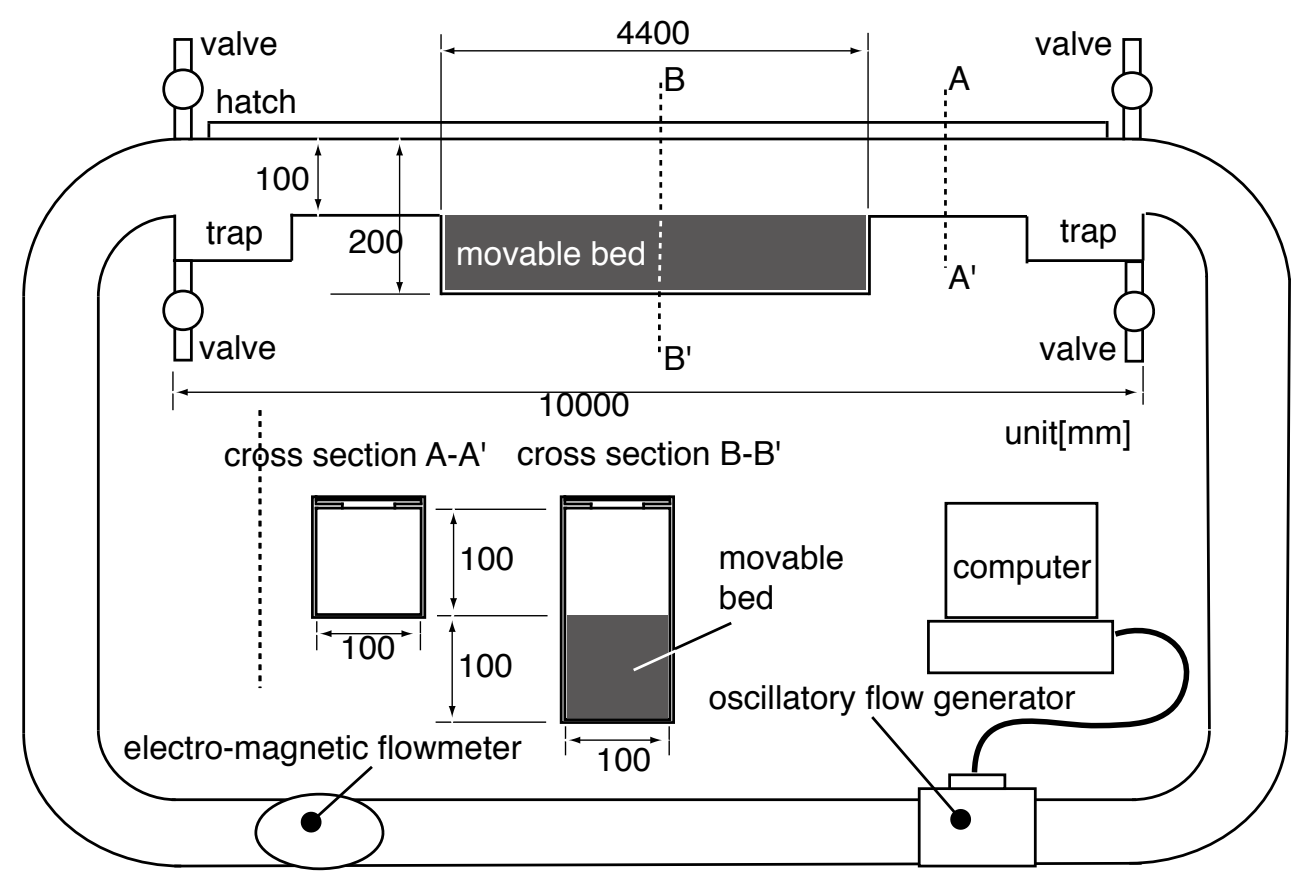

Fig. 1 Oscillatory flow tunnel

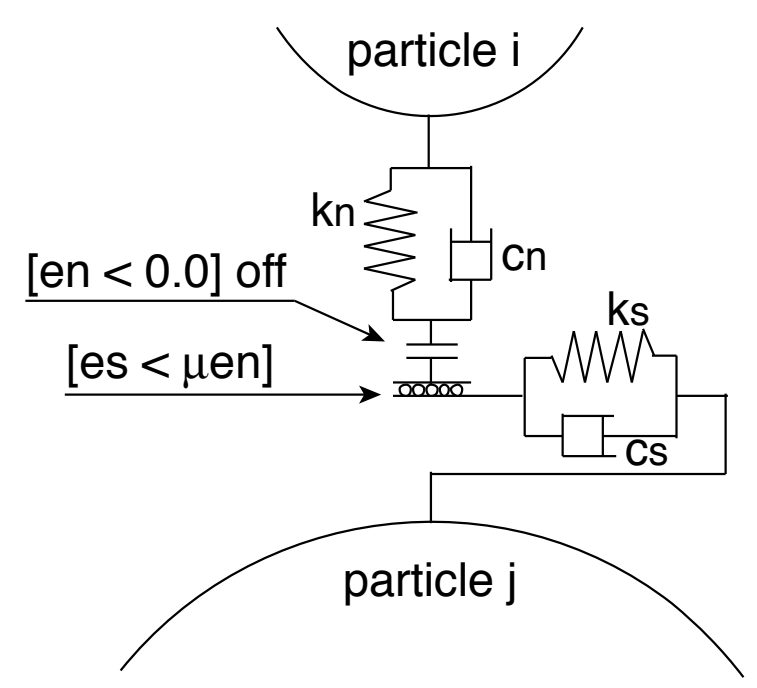

Fig. 2 Voigt model (spring-dashpot system) 


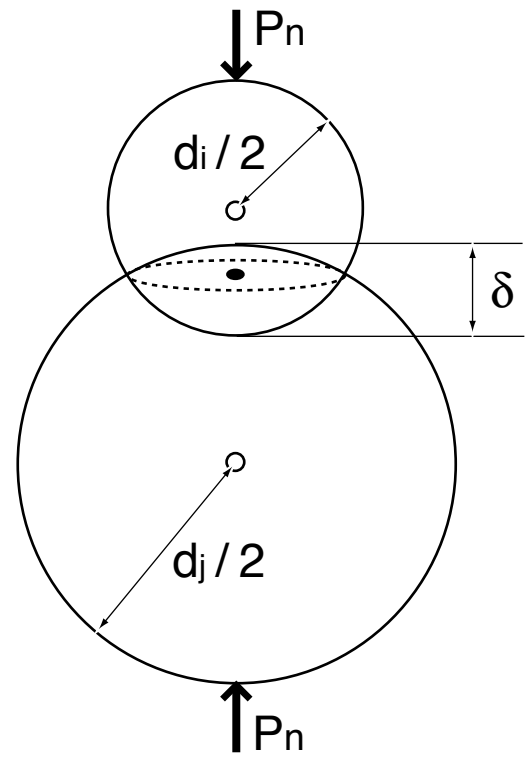

Fig. 3 Heltz's elasticity contact theory

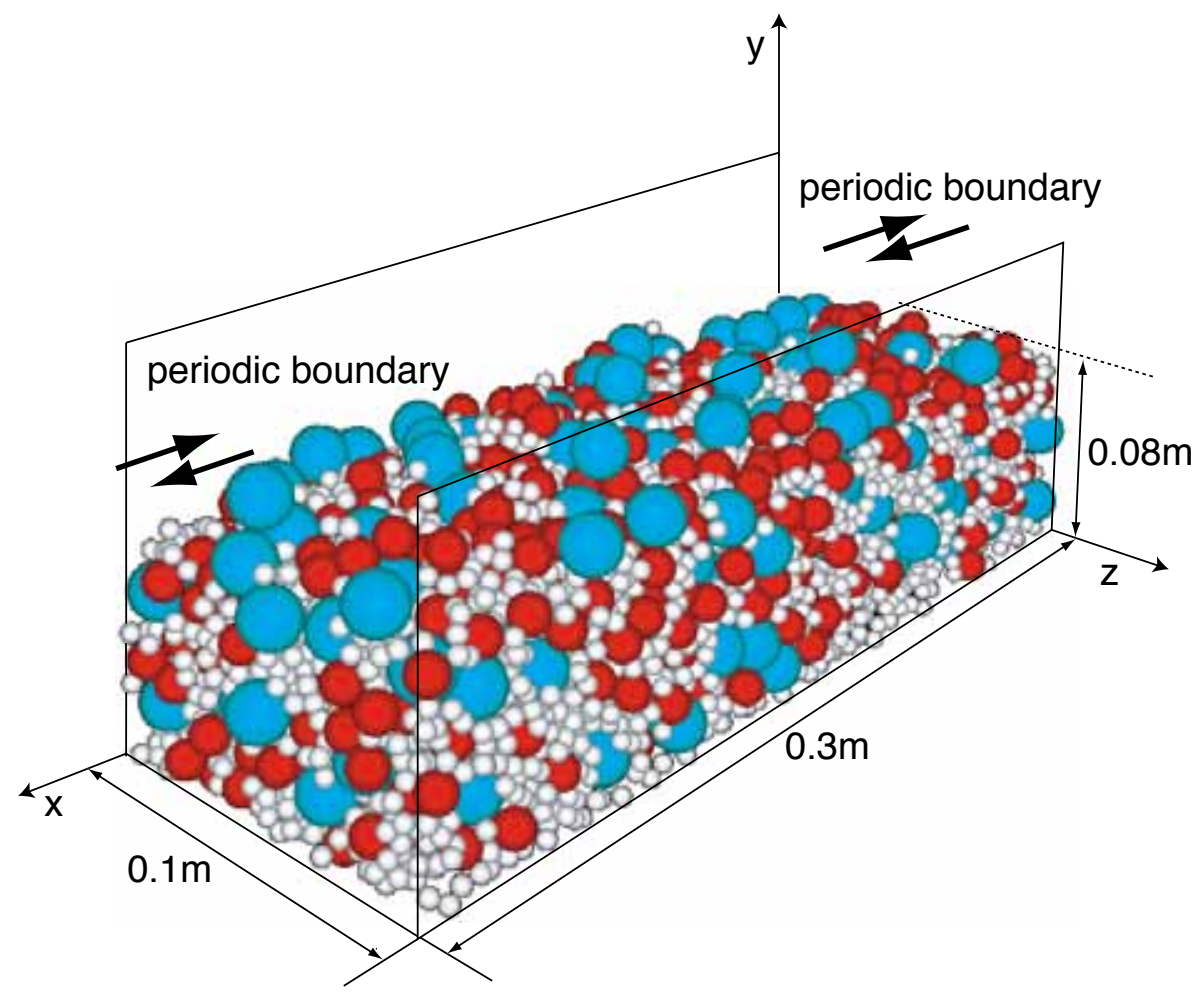

Fig. 4 Calculated domain 


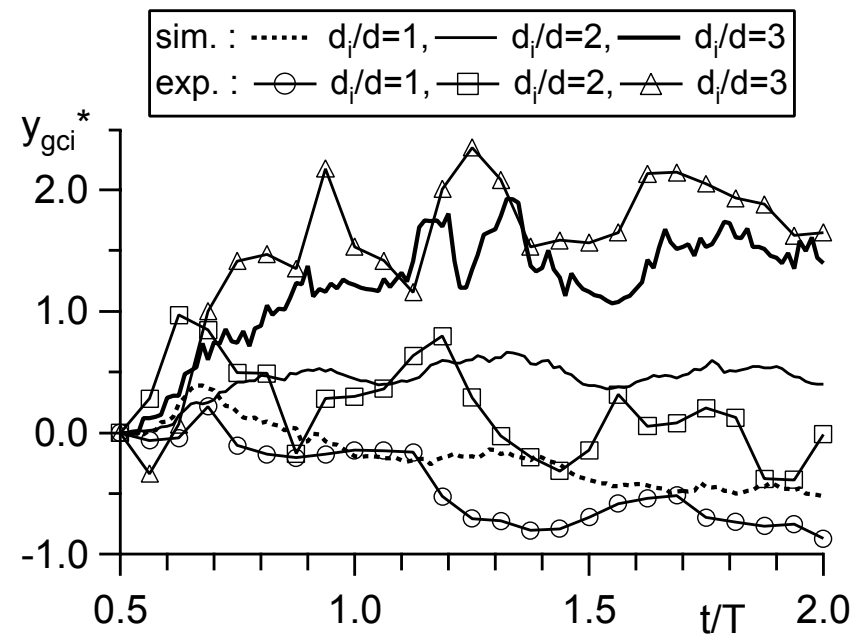

Fig. 5 Time series of centroids of concentration of particles

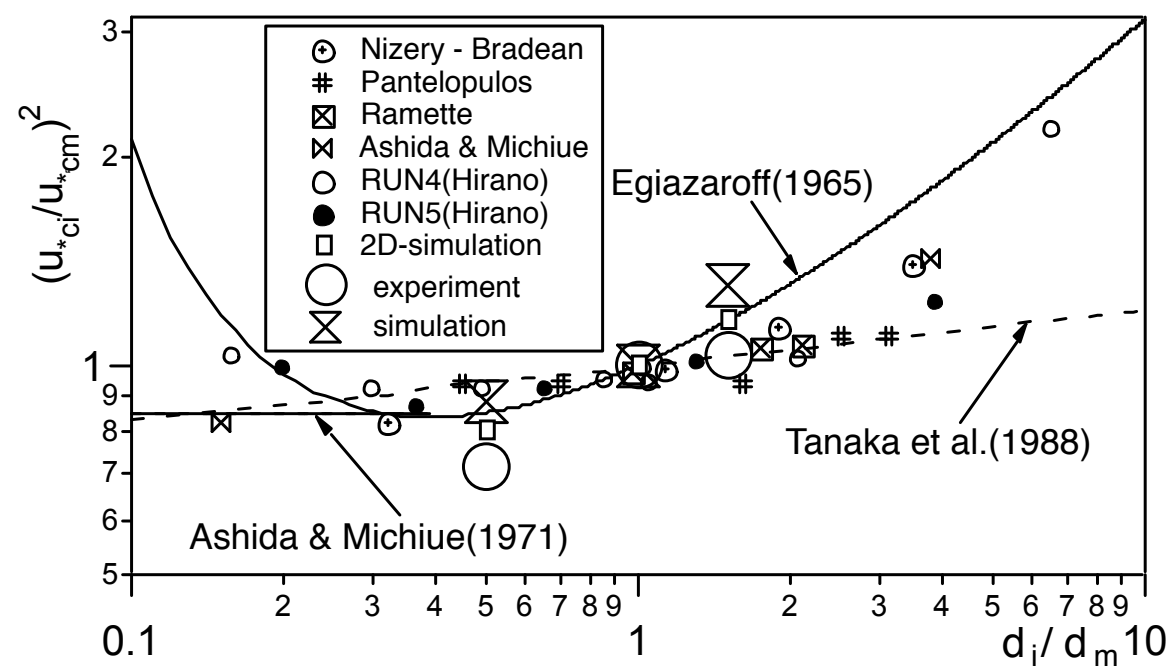

Fig. 6 Critical state of movement of each diameter class 

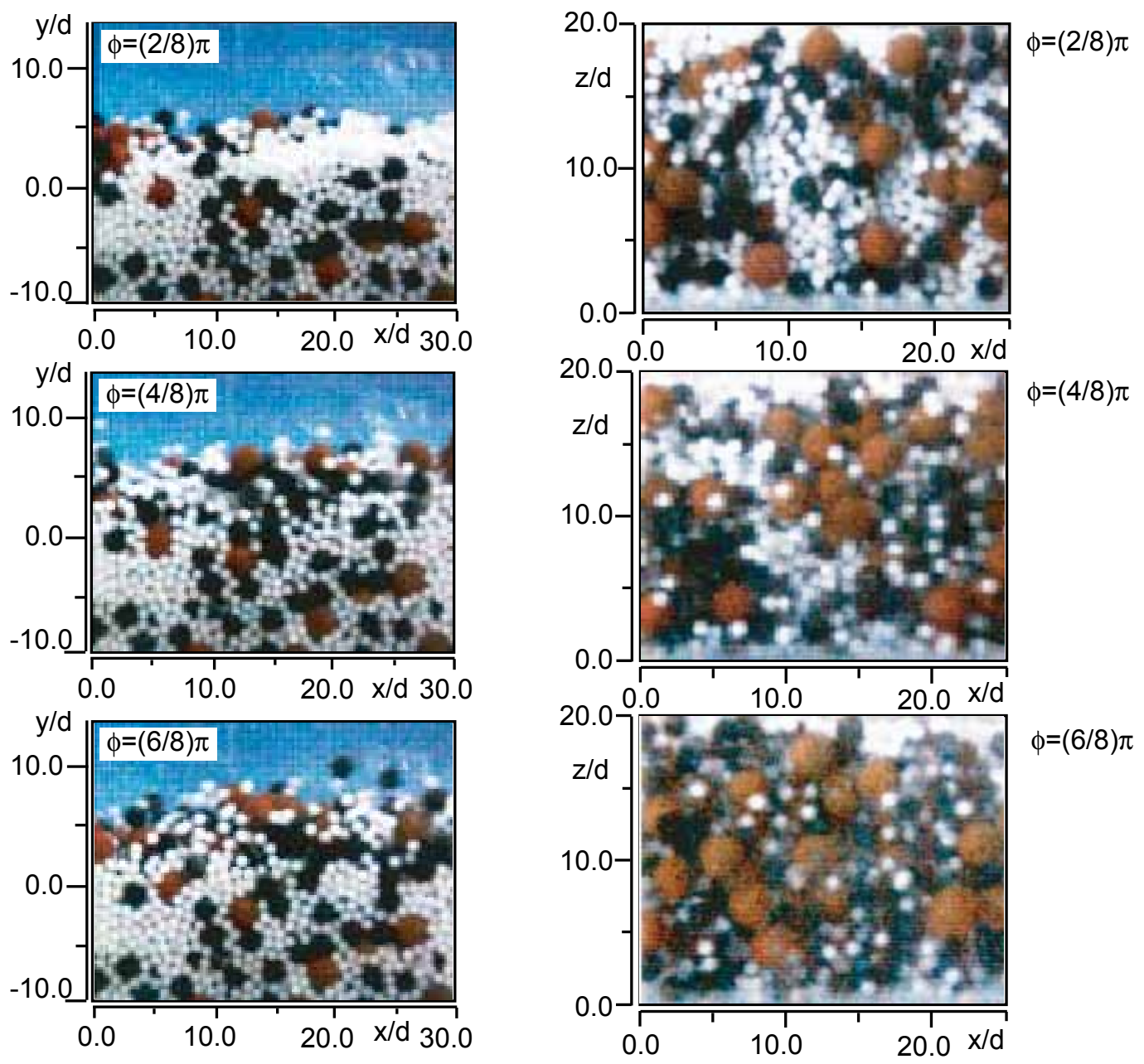

(a) side view [exp.]

(b) top view [exp.]
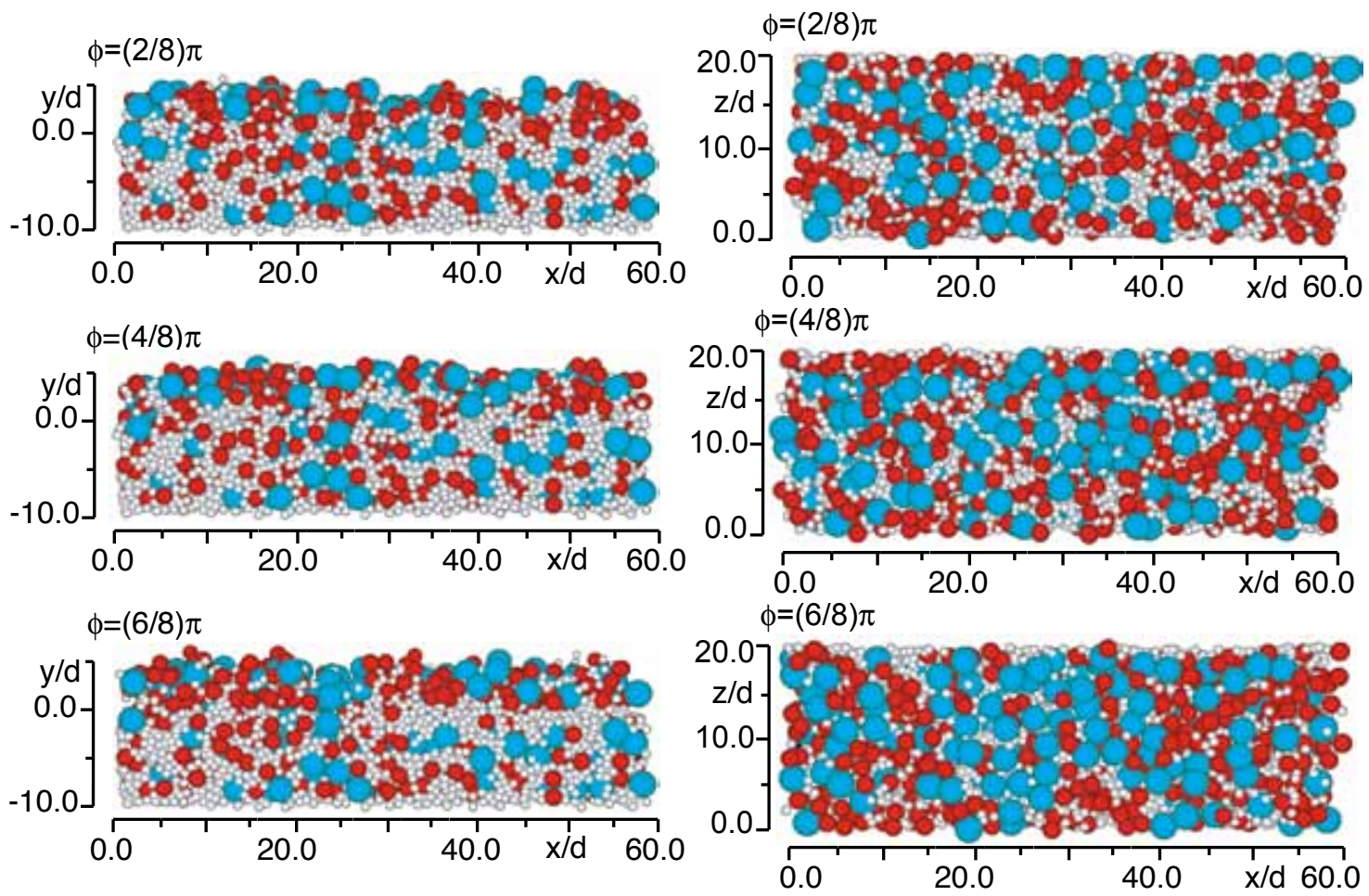

(c) side view [sim.]

(d) top view [sim.]

Fig. 7 Comparison between experimental video images an computational snapshots in developing stage of grading 

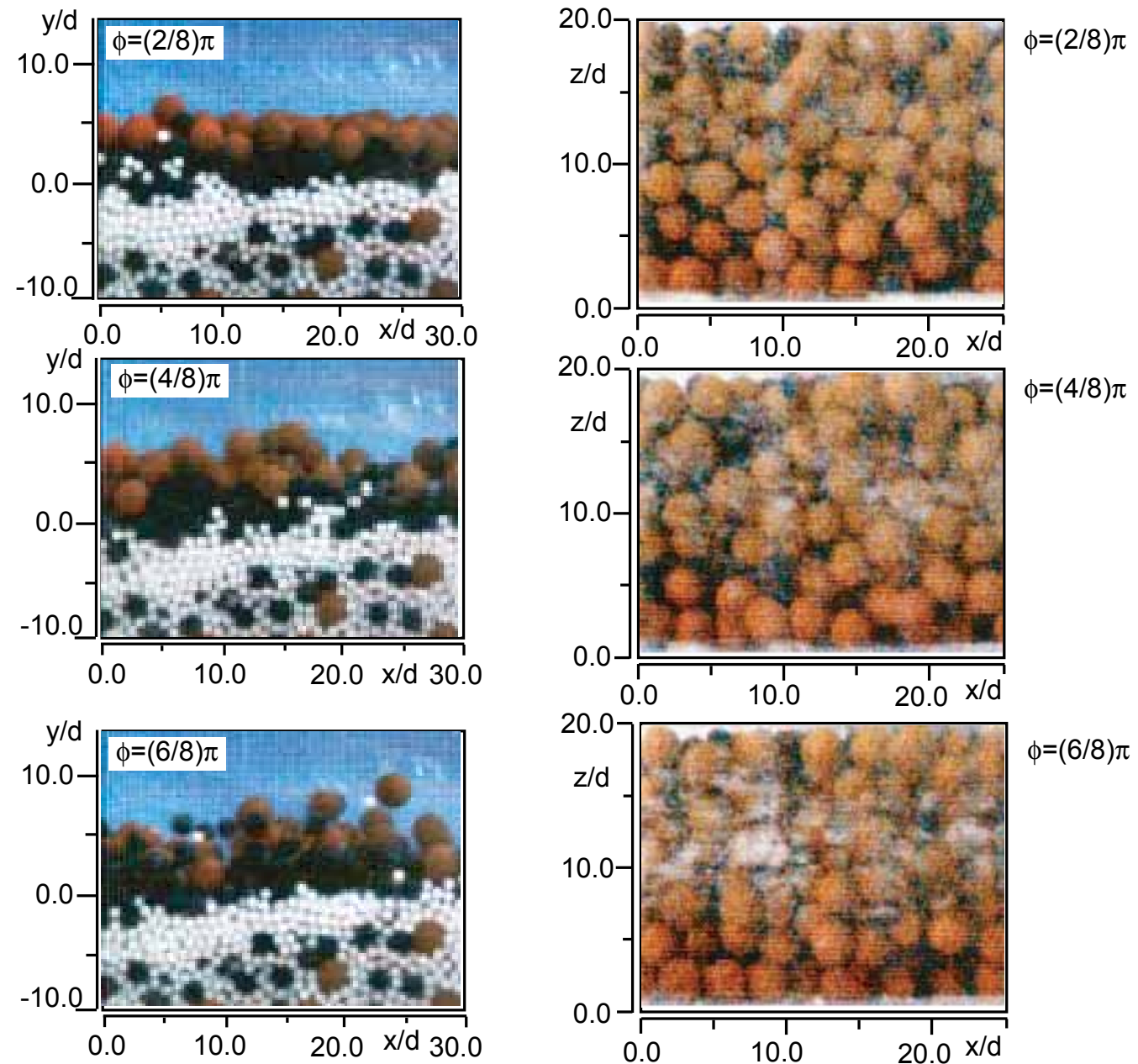

(a) side view [exp.]

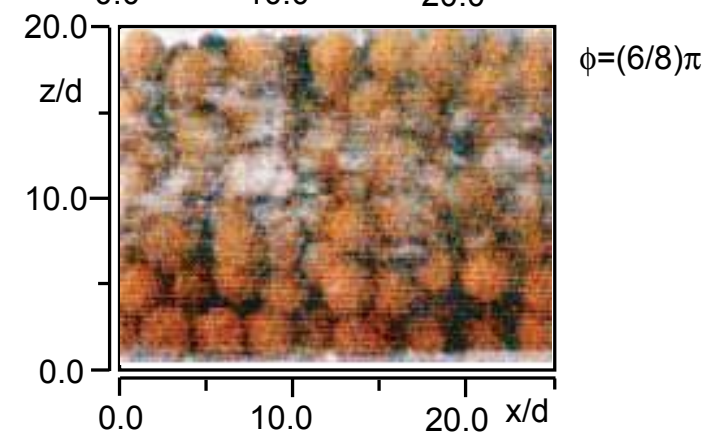

(b) top view [exp.]

$\phi=(2 / 8) \pi$
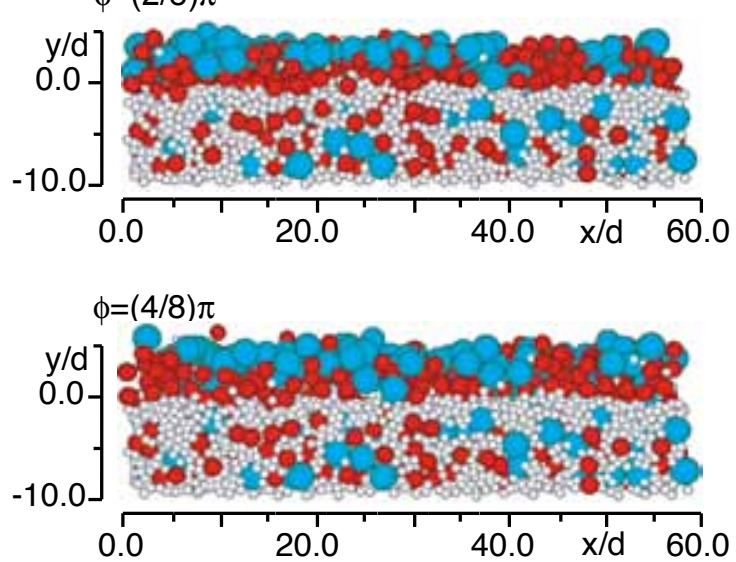

$\phi=(6 / 8) \pi$

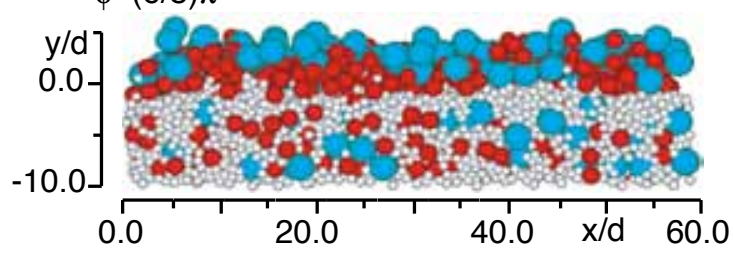

(c) side view [sim.] $\phi=(2 / 8) \pi$

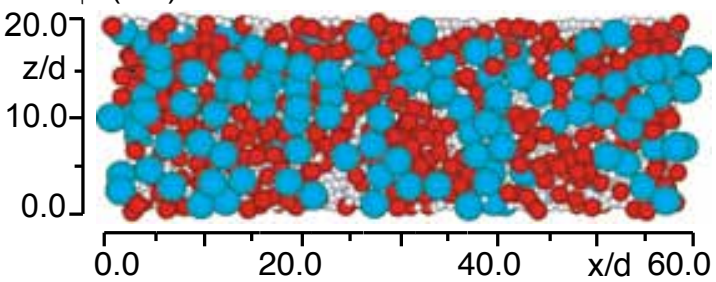

$\phi=(4 / 8) \pi$

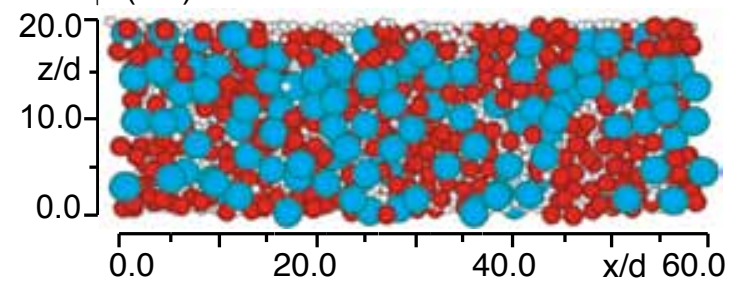

$\phi=(6 / 8) \pi$

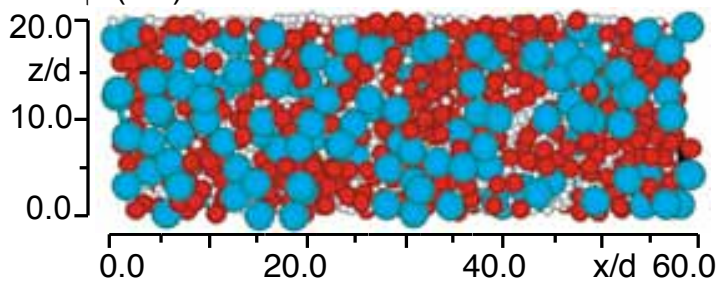

(d) top view [sim.]

Fig. 8 Comparison between experimental video images an computational snapshots in fully developed stage of grading 


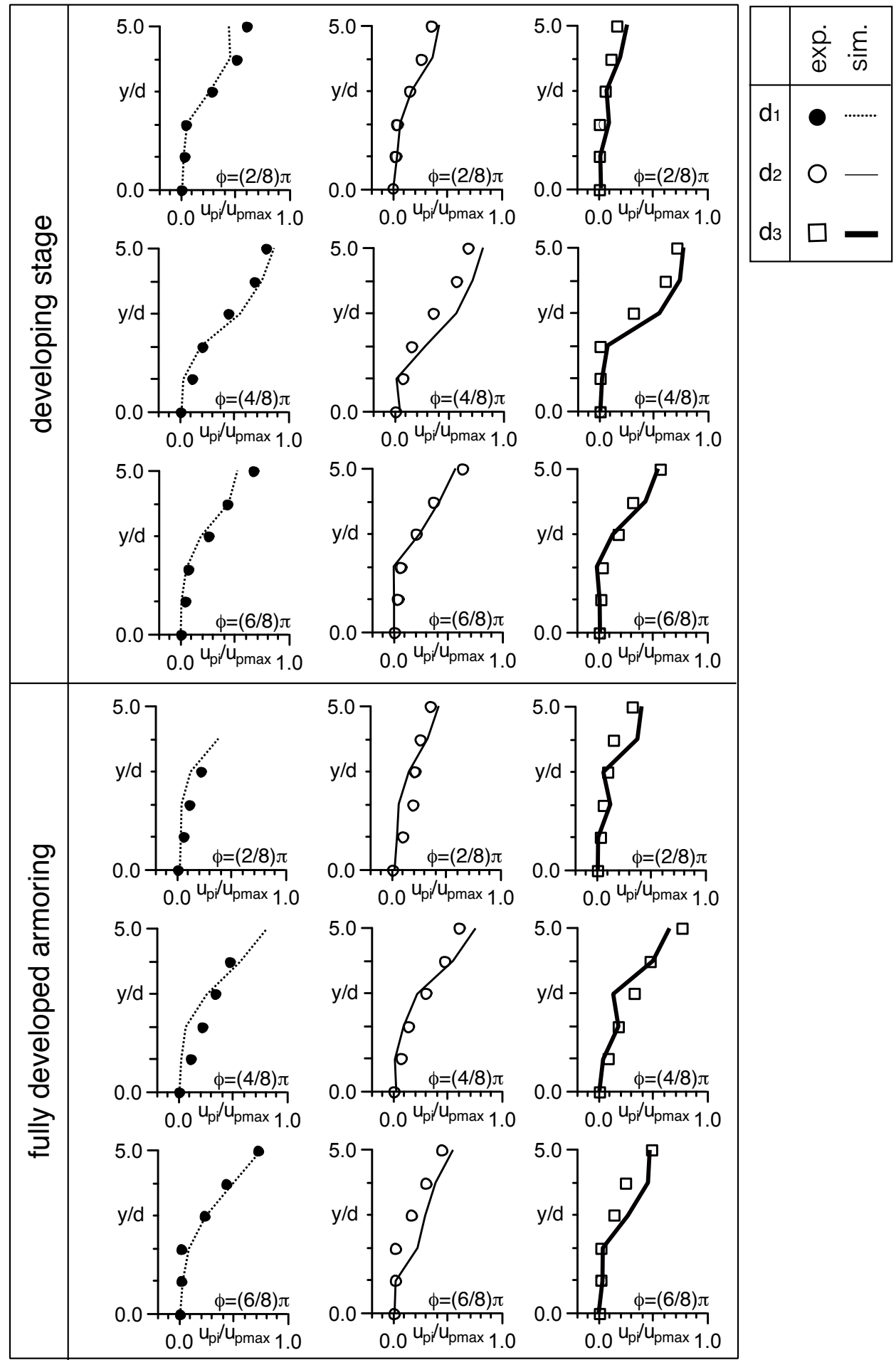

Fig. 9 Mean velocity profiles of sediment particles 


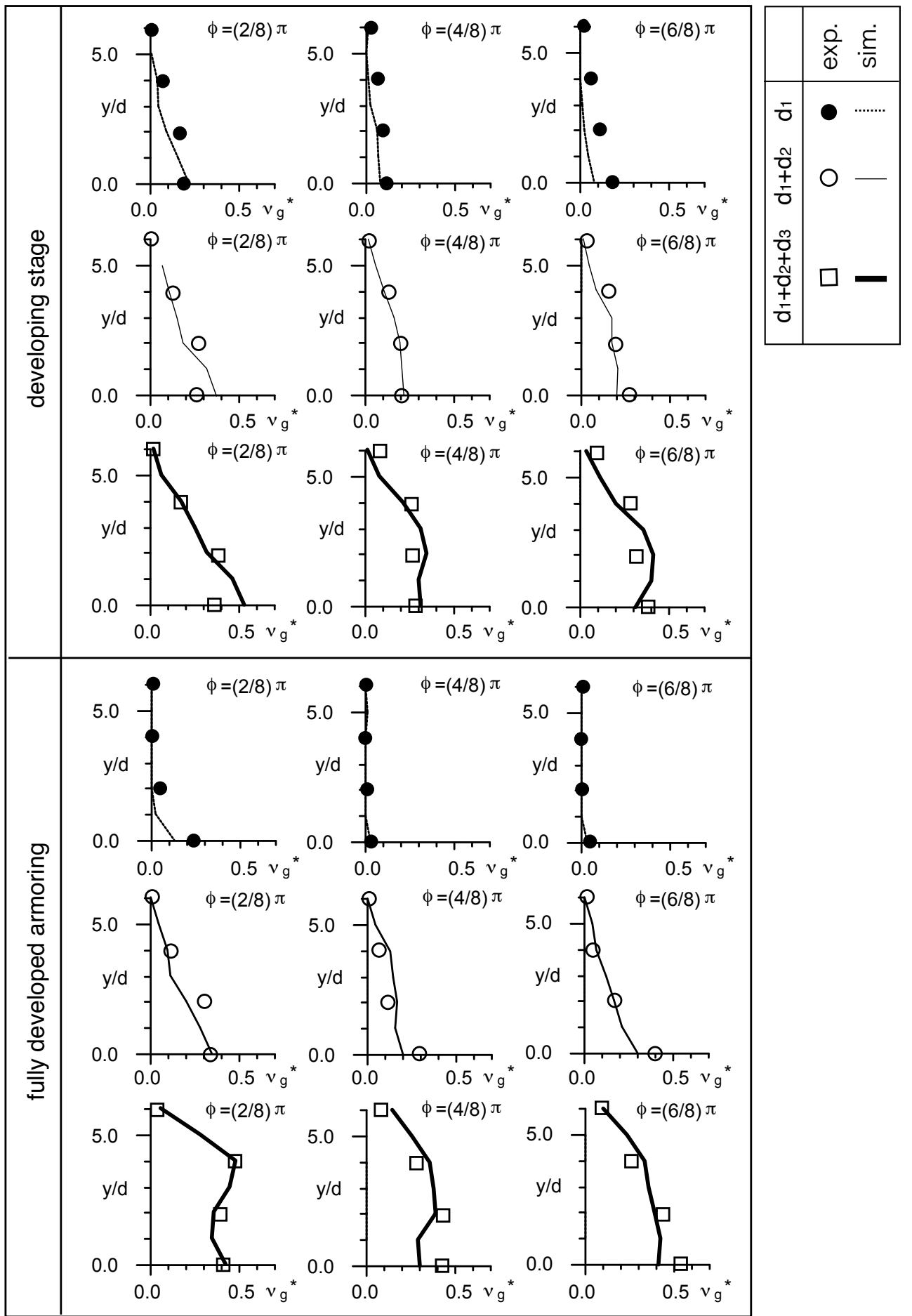

Fig. 10 Dimensionless particle number density distributions 


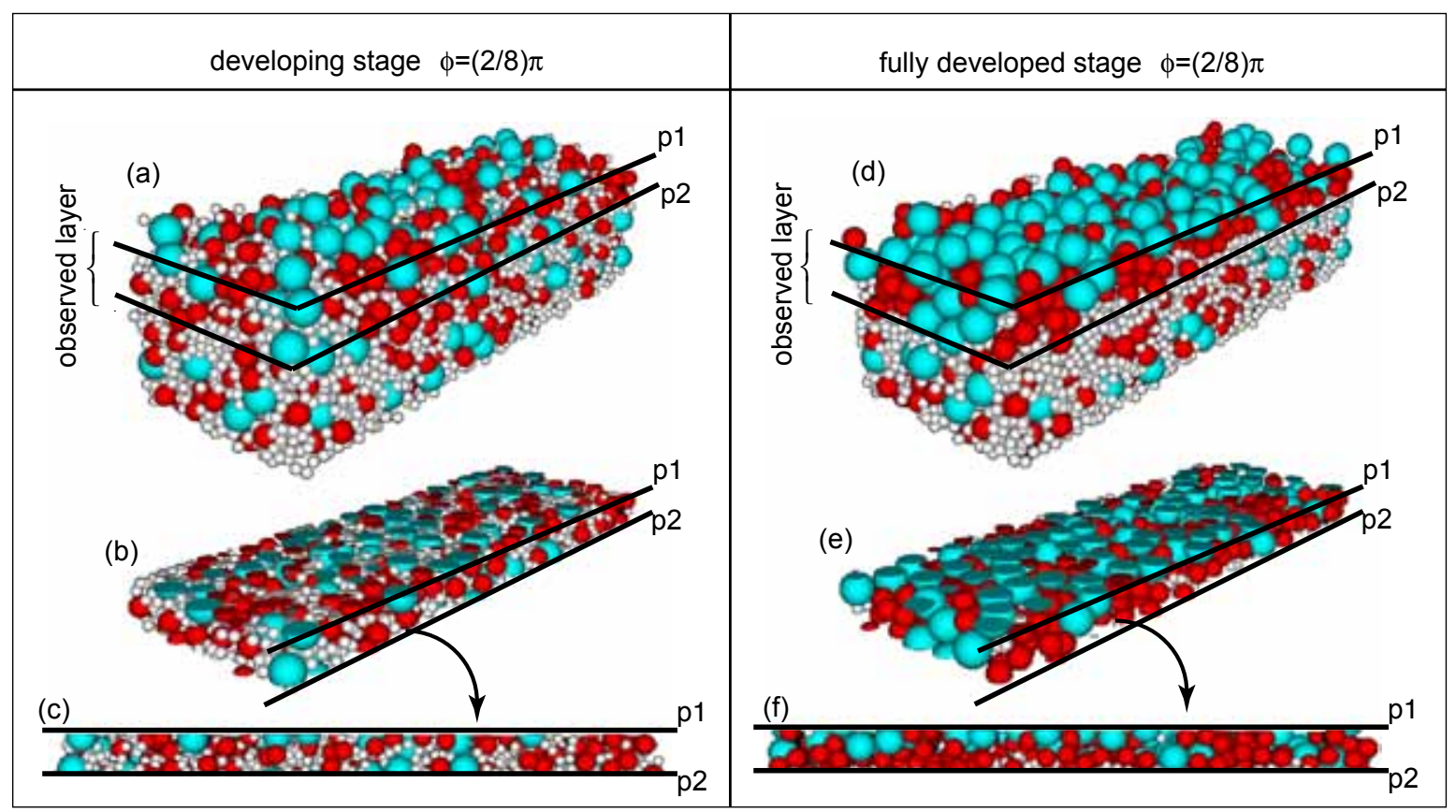

Fig. 11 Estimation of dimensionless particle number density

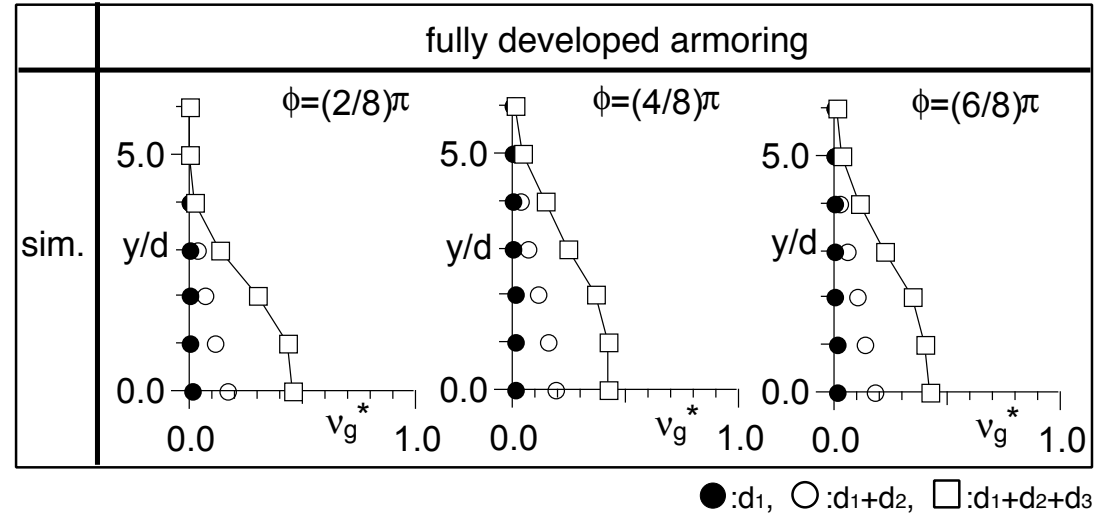

Fig. 12 Dimensionless particle number density distributions 


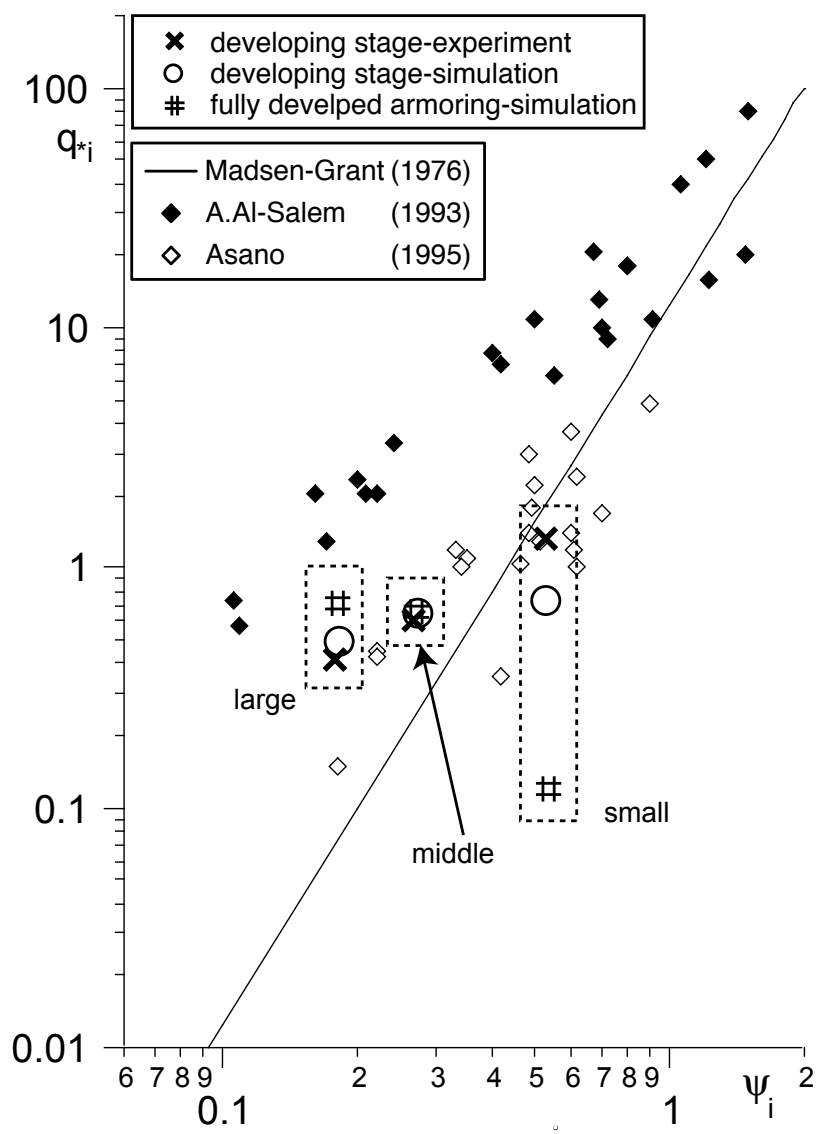

Fig. 13 Sediment transport rate 

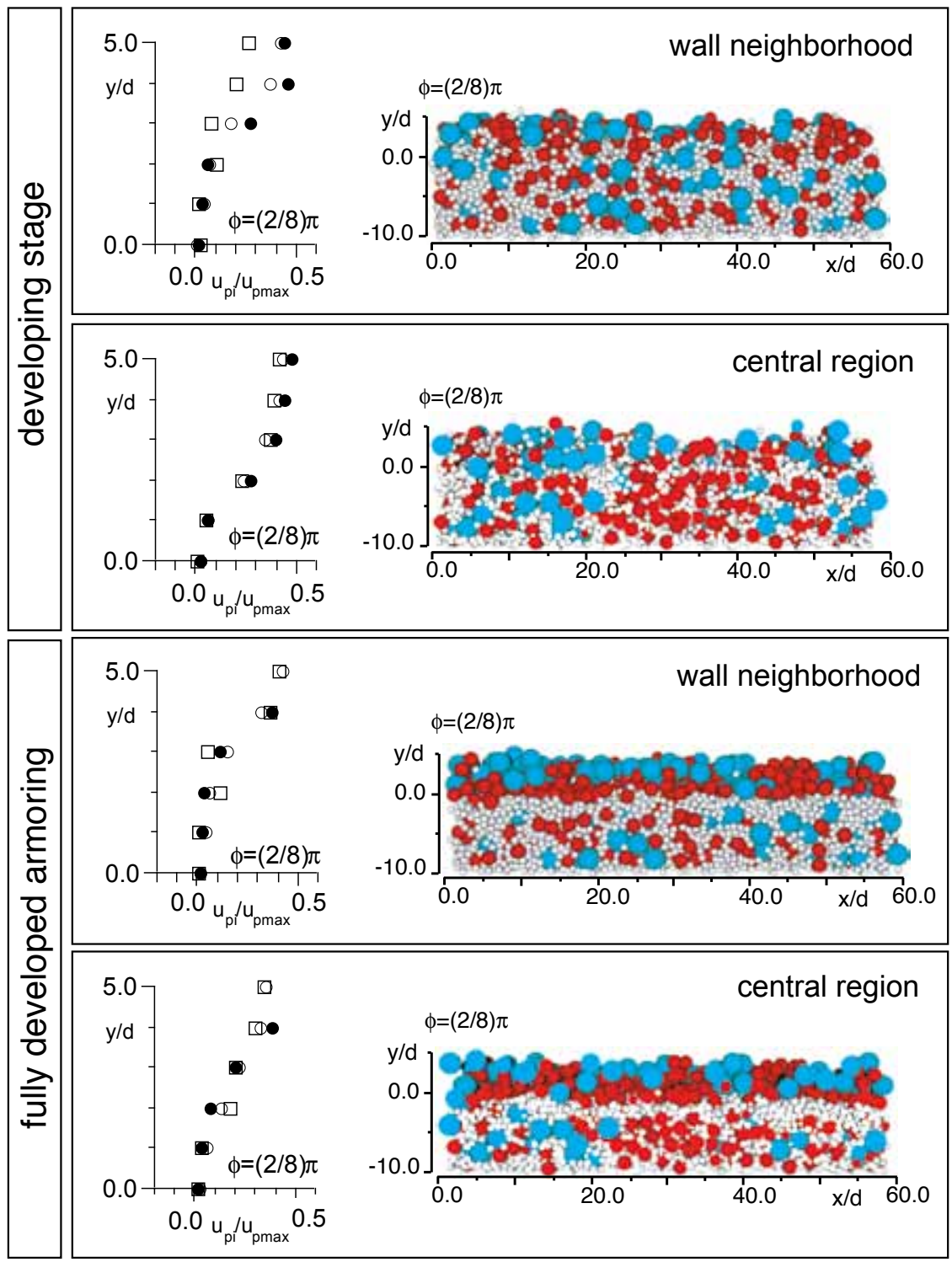

$: \mathrm{d}_{1}, \mathrm{O}: \mathrm{d}_{2}, \square: \mathrm{d}_{3}$

Fig. 14 Comparison of internal structure of sheetflow layer 


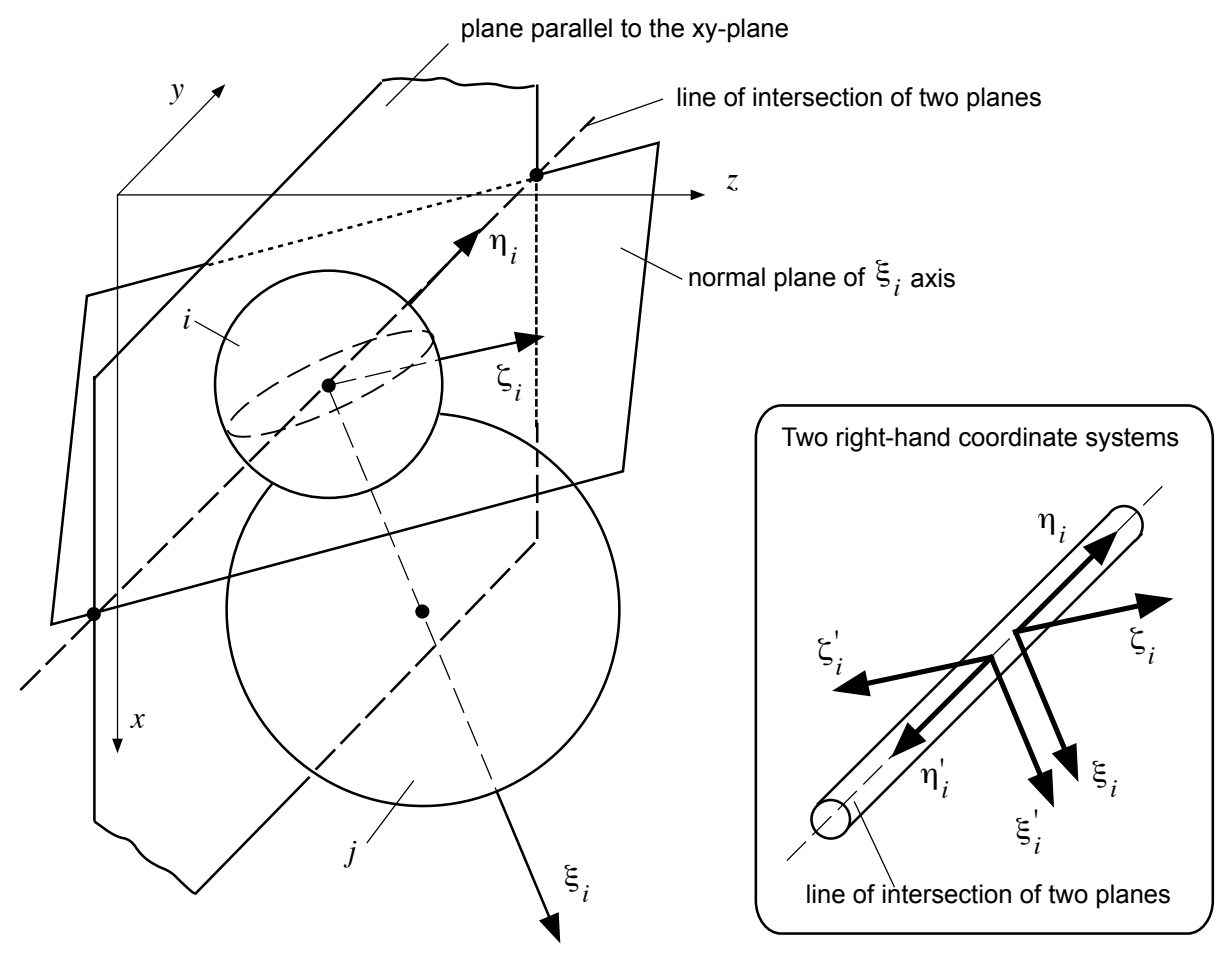

Fig. 15 Local coordinate

Table 1 Sediment diameter class

\begin{tabular}{|c||c|c|c|}
\hline Class $\mathrm{k}$ & $\mathrm{dk}(\mathrm{mm})$ & $\mathrm{f} 0 \mathrm{k}$ & $\mathrm{dk} / \mathrm{dm}$ \\
\hline 1 & 5.15 & 0.333 & 0.504 \\
2 & 9.88 & 0.333 & 0.968 \\
3 & 15.60 & 0.333 & 1.528 \\
\hline
\end{tabular}

